\title{
New Series of Ternary Metal Chloride Superionic Conductors for High Performance All-Solid-State Lithium Batteries
}

Jianwen Liang

Western University

Eveline van der Maas

Delft University of Technology

Jing Luo

Western University

Xiaona Li

Western University

Ning Chen

Canadian Light Source

Keegan Adair

Western University

Weihan Li

Western University

Yongfeng $\mathrm{Hu}$

Canadian Light Source (Canada)

Junjie Li

Western University

Li Zhang

China Automotive Battery Research Institute

Shangqian Zhao

China Automotive Battery Research Institute

Shigang Lu

China Automotive Battery Research Institute

Jiantao Wang

China Automotive Battery Research Institute Co. Ltd

Huan Huang

Glabat Solid-State Battery Inc.

\section{Steven Parnell}

Delft University of Technology

Ronald Smith 
ISIS Facility https://orcid.org/0000-0002-4990-1307

\section{Swapna Ganapathy}

Department of Radiation Science and Technology, Delft University of Technology https://orcid.org/0000-0001-5265-1663

\section{Marnix Wagemaker}

Department of Radiation Science and Technology, Delft University of Technology https://orcid.org/0000-0003-3851-1044

\section{Xueliang Sun ( $\nabla$ xsun9@uwo.ca )}

Western University https://orcid.org/0000-0003-0374-1245

\section{Article}

Keywords: halide superionic conductors, lithium batteries, electrochemical performance

Posted Date: February 12th, 2021

DOl: https://doi.org/10.21203/rs.3.rs-150360/v1

License: (c) (1) This work is licensed under a Creative Commons Attribution 4.0 International License. Read Full License

Version of Record: A version of this preprint was published at Advanced Energy Materials on April 7th, 2022. See the published version at https://doi.org/10.1002/aenm.202103921. 


\section{Abstract}

Understanding the relationship between structure, ionic conductivity, and synthesis is the key to the development of solid electrolytes for all-solid-state Lithium batteries. Here, we investigate chloride solid electrolytes with compositions $\mathrm{Li}_{3}-3 x \mathrm{M}_{1+x} \mathrm{Cl}_{6}(-0.14<x \leq 0.5, \mathrm{M}=\mathrm{Tb}, \mathrm{Dy}, \mathrm{Ho}, \mathrm{Y}, \mathrm{Er}, \mathrm{Tm})$. When $x>0.04, \mathrm{a}$ trigonal to orthorhombic phase transition occurs in the isostructural $\mathrm{Li}-\mathrm{Dy}-\mathrm{Cl}, \mathrm{Li}-\mathrm{Ho}-\mathrm{Cl}, \mathrm{Li}-\mathrm{Y}-\mathrm{Cl}, \mathrm{Li}-\mathrm{Er}-\mathrm{Cl}$ and $\mathrm{Li}-\mathrm{Tm}-\mathrm{Cl}$ solid electrolytes. The new orthorhombic phase shows a four-fold increase in ionic conductivity up to $1.3 \times 10^{-3} \mathrm{~S} \mathrm{~cm}^{-1}$ at room temperature for $\mathrm{Li}_{2.73} \mathrm{Ho}_{1.09} \mathrm{Cl}_{6}(x=0.09)$ when compared to the trigonal $\mathrm{Li}_{3} \mathrm{HoCl}_{6}$. For isostructural $\mathrm{Li}-\mathrm{Dy}-\mathrm{Cl}, \mathrm{Li}-\mathrm{Y}-\mathrm{Cl}, \mathrm{Li}-\mathrm{Er}-\mathrm{Cl}$ and $\mathrm{Li}-\mathrm{Tm}-\mathrm{Cl}$ solid electrolytes, about one order of magnitude increase in ionic conductivities are observed for the orthorhombic structure compared to the trigonal structure. Using the $\mathrm{Li}-\mathrm{Ho}-\mathrm{Cl}$ components as an example, detailed studies of its structure, phase transition, ionic conductivity, air stability and electrochemical stability have been made. Molecular dynamics simulations based on density functional theory reveal that the different cations arrangement in the orthorhombic structure leads to a higher lithium diffusivity as compared to the trigonal structure, rationalizing the improved ionic conductivities of the new Li-M-Cl electrolytes. All-solid-state batteries of

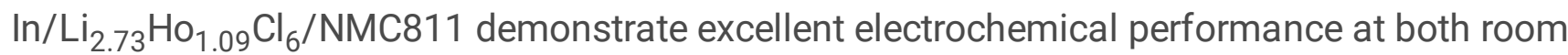
temperature and $-10^{\circ} \mathrm{C}$. As relevant to the vast number of isostructural halide electrolytes, the present structure control strategy provides guidance for the design of novel halide superionic conductors.

\section{Introduction}

The development of high-performance all-solid-state batteries is contingent on the finding and synthesis of solid-state electrolytes (SSEs) with high ionic conductivity, good chemical and ambient air stability, wide electrochemical window, and desirable mechanical properties, especially for the applications in electric and hybrid electric vehicles ${ }^{1-4}$. Recently, several families of SSEs have attracted significant interest, such as metal sulfides or oxides with polyanionic frameworks $\left(\mathrm{PS}_{4}{ }^{3-}, \mathrm{PO}_{4}{ }^{3-}\right.$ etc. $)$ and metal halides with close packed anion sub-lattice structures ${ }^{5-10}$. Among these candidates, a promising family of metal chloride SSEs generally possess a wide electrochemical stability window $(\sim 4 \mathrm{~V})$, good chemical stability towards ambient air and cathode materials (e.g. $\left.\mathrm{LiCoO}_{2}\right)$. Some of them can be even synthesized at large scales from aqueous solutions ${ }^{6,11-14}$. Although chloride-based SSEs have been developed over the past decades ${ }^{15-18}$, their use has been limited due to their low ionic conductivities. Until now, only a few metal chloride SSEs have achieved high room-temperature (RT) ionic conductivities over $10^{-4} \mathrm{~S} \mathrm{~cm}^{-}$ , including $\mathrm{Li}_{3} \mathrm{YCl}_{6}{ }^{14}, \mathrm{Li}_{3} \operatorname{lnCl}_{6}{ }^{19}, 20, \mathrm{Zr}$ doped $\mathrm{Li}_{3} \mathrm{MCl}_{6}(\mathrm{M}=\mathrm{Y}, \mathrm{Er})^{21}, \mathrm{Li}_{3} \mathrm{Y}_{1-x} \mathrm{In}_{x} \mathrm{Cl}_{6}{ }^{22}, \mathrm{Li}_{x} \mathrm{ScCl}_{3+x}{ }^{23}$ and $\mathrm{Li}_{2} \mathrm{Sc}_{2 / 3} \mathrm{Cl}_{4}{ }^{24}$. In the search for new metal-chloride SSEs, it is unclear whether the lack of good chloride conductors is intrinsic due to the different anionic framework structure or a result of the fact that they may be difficult to synthesize, which demands better understanding of the relationship between structure and ionic conductivity ${ }^{19,25,26}$. 
Ternary chloride with the composition of $\mathrm{Li}_{3} \mathrm{M}(\mathrm{III}) \mathrm{Cl}_{6}$, where $\mathrm{M}(\mathrm{III})$ represents a trivalent rare earth metal, can crystallize in three types of structures including monoclinic $(C 2 / m)$, trigonal $(P-3 m 7)$, and orthorhombic (Pnma) phase ${ }^{6,18}$. Because the ionic radius of $\mathrm{Cl}^{-}$is typically much larger than that of the $\mathrm{M}^{3+}$ ions, the $\mathrm{Cl}^{-}$sub-lattice forms the framework of these structures, where the interstitial sites are occupied by the $\mathrm{Li}^{+}$and $\mathrm{M}^{3+}$ ions. The monoclinic structure occurs with relatively small metal radii, such as In or Sc. The $\mathrm{Cl}^{-}$sub-lattice forms a cubic close packing ( $\left.c c p\right)$ stacking. In both the trigonal and orthorhombic structures, the $\mathrm{Cl}^{-}$sub-lattice is stacked in a hexagonal close packing (hcp) fashion. The $h c p$ halogen stacking is interesting in view of structural diversity and Li-ion conductivity as it provides 6 octahedral and 12 tetrahedral interstitial sites in the $\mathrm{Cl}^{-}$sub-lattice per formula unit, with only 4 cations to occupy them. The specific cation and vacancy arrangements imposed by the different symmetry of the trigonal and orthorhombic structures can be expected to result in distinct $\mathrm{Li}^{+}$transport properties. Understanding the interrelationship of the structures and the $\mathrm{Li}^{+}$conducting behaviors can help us to design favorable structures towards higher ionic conductivities. Also, in the competition between the hcp stacked trigonal and orthorhombic structures, the average metal radius has been suggested to play a decisive role ${ }^{6}$, where the structures crystallize in the Pnma space group with smaller trivalent metal ions (Yb, Lu) and in the $P-3 m 1$ the space group with larger metal ions (Tb, Dy, Ho, Er, Tm) at room temperature. Only $\mathrm{Li}_{3} \mathrm{YCl}_{6}$ has been reported in both space groups, while the Pnma phase is metastable. That was explained by an order-disorder phase transition connecting the two phases, with a phase transition temperature close to room temperature ${ }^{18}$.

Herein, we investigate the interplay between composition, structure, and Li-ion conductivity through the preparation of a series of $\mathrm{Li}-\mathrm{M}(\mathrm{III})-\mathrm{Cl}$ SSEs synthesized by co-melting of $\mathrm{LiCl}$ and $\mathrm{MCl}_{3}$. Using $\mathrm{Li}-\mathrm{Ho}-\mathrm{Cl}$ as example, by controlling the ratio between $\mathrm{Li}$ and $\mathrm{Ho}$, a new series of orthorhombic-structured $\mathrm{Li}_{3}$ ${ }_{3 x} \mathrm{Ho}_{1+x} \mathrm{Cl}_{6}(0.04<x \leq 0.2$, space group Pnma) were synthesized for the first time. This orthorhombic Li$\mathrm{Ho}-\mathrm{Cl}$ material shows a cold-pressed ionic conductivity up to $1.3 \times 10^{-3} \mathrm{~S} \mathrm{~cm}^{-1}$ at room temperature. That is over four-fold greater than the $\mathrm{Li}_{3} \mathrm{HoCl}_{6}$ with a trigonal structure $(P-3 m 1)$. Benefiting from the high ionic conductivity as well as the wide electrochemical window of $\mathrm{Li}-\mathrm{Ho}-\mathrm{Cl}$ materials, the all-solid-state batteries with an In/Li-Ho-Cl/NMC811 configuration demonstrate excellent electrochemical performance at room temperature and $-10^{\circ} \mathrm{C}$. A detailed structural investigation is combined with molecular dynamics simulations to reveal the relationship between structure and Li-ion conductivity. Moreover, similar trigonalto-orthorhombic phase transition phenomenon is reproducible in all $\mathrm{Li}-\mathrm{M}(\mathrm{III})-\mathrm{Cl}(\mathrm{M}=\mathrm{Y}, \mathrm{Er}, \mathrm{Dy}, \mathrm{Tm})$ structure with a $P-3 m 1$ space group except $\mathrm{Li}-\mathrm{Tb}-\mathrm{Cl}$ component. The structural transition induced by altering the ratio of $\mathrm{Li}^{+}$to $\mathrm{M}^{3+}$ cations indicates that not only the average $\mathrm{M}^{3+}$ radius but also the average cation (including both $\mathrm{Li}^{+}$and $\mathrm{M}^{3+}$ ) size plays an important role in determining the structure. About one order of magnitude different in ionic conductivities is observed in the isostructural $\mathrm{Li}-\mathrm{Dy}-\mathrm{Cl}, \mathrm{Li}-\mathrm{Y}-\mathrm{Cl}, \mathrm{Li}-\mathrm{Er}-\mathrm{Cl}$, and Li$\mathrm{Tm}-\mathrm{Cl}$ compositions. The increase in ionic conductivity from the trigonal to the orthorhombic phases is rationalized by the fact that the more regular orthorhombic phase results in easier $\mathrm{Li}^{+}$transport along the c-lattice direction (between the $8 d 1$ and $8 d 2$ Wykoff sites) which is a critical step in the diffusion network. These new insights into the relationship of ionic conductivity, chemical composition, and structure 
provide a new opportunity for halide solid electrolytes design and for the ultimate pursuit of highly conductive, stable, and processable solid electrolytes as required for all-solid-state batteries.

\section{Results And Discussion}

The halide SSEs based on the Li-Ho-Cl system were synthesized from a stoichiometric mixture of binary compound precursors $\left(\mathrm{LiCl}\right.$ and $\mathrm{HoCl}_{3}$ ) directly by co-melting at $650^{\circ} \mathrm{C}$ for $24 \mathrm{~h}$. Figures $1 \mathrm{a}, \mathrm{b}$ and $\mathrm{S} 1$ show the X-ray diffraction (XRD) patterns of $\mathrm{Li}_{3}{ }_{-3 x} \mathrm{Ho}_{1+x} \mathrm{Cl}_{6}$ SSE materials over the range of $x$ from -0.14 to 0.5. When the value of $x$ is lower than 0.02 , such as $\mathrm{Li}_{2.95} \mathrm{Ho}_{1.017} \mathrm{Cl}_{6}$ (Figure $\mathrm{S} 1 x=0.017$ ), $\mathrm{Li}_{3} \mathrm{HoCl}_{6}$ (Fig. $1 \mathrm{a}, \mathrm{x}=0$ ) and $\mathrm{Li}_{3.42} \mathrm{Ho}_{0.86} \mathrm{Cl}_{6}$ (Fig. $1 \mathrm{a}, \mathrm{x}=-0.14$ ), the products can be indexed to a previously reported trigonal structure with the space group of $P-3 m 1$ (ICSD No. 04-009-8880). In contrast, when the value of $x$ is in the range from 0.04 to 0.2 , a new $\mathrm{Li}_{3}-3 x \mathrm{Ho}_{1+x} \mathrm{Cl}_{6}$ structure is obtained. As shown in Figs. $1 \mathrm{~b}$ and $\mathrm{S} 1$, the XRD patterns of $\mathrm{Li}_{2.4} \mathrm{Ho}_{1.2} \mathrm{Cl}_{6}(x=0.2), \mathrm{Li}_{2.73} \mathrm{Ho}_{1.09} \mathrm{Cl}_{6}(x=0.09)$, and $\mathrm{Li}_{2.87} \mathrm{Ho}_{1.043} \mathrm{Cl}_{6}(x=0.043)$ are quite different from that of the trigonal structure of $\mathrm{Li}_{3} \mathrm{HoCl}_{6}$. Peaks indexing of the XRD pattern reveals that the new phase has an orthorhombic unit cell with cell parameters of $a=12.9 \AA, b=11.2 \AA$, and $c=6.0$ $\AA$. Obedience to the extinction rules of $h 00: h=2 n, 0 k 0: k=2 n, 00 l: I=2 n, 0 k l: k+l=2 n+1, h k 0: h=2 n+$ 1 is characteristic of the Pnma space group.

The structure of the Pnma phase was confirmed by Rietveld refinement of the XRD patterns (Figure S2) as well as the neutron powder diffraction (NPD) of the three highest resolution detector banks (Figs. 1C, $d$ and S3) of the material with nominal starting stoichiometry $\mathrm{Li}_{2.72} \mathrm{Ho}_{1.09} \mathrm{Cl}_{6}(x=0.09)$. The refinement converged to the final stoichiometry of $\mathrm{Li}_{2.42} \mathrm{Ho}_{1.13} \mathrm{Cl}_{6}$. The lattice parameters converged to $\mathrm{a}=12.95 \AA \mathrm{A}, \mathrm{b}$ $=11.79 \AA$ and $c=6.04 \AA$, which are very close to those of the Pnma-phase $\mathrm{Li}_{3} \mathrm{YCl}_{6}{ }^{18}(\mathrm{a}=12.930 \AA \mathrm{A}, \mathrm{b}=$ $11.121 \AA$, $c=6.040 \AA$ ) $)$. The atomic positions in the Li-Ho-Cl SSE are similar to the corresponding sites in $\mathrm{Li}_{3} \mathrm{YCl}_{6}$, with slightly smaller values in $\mathrm{z}$-coordinate of the $\mathrm{Li}$ sites and slightly larger values in $\mathrm{x}$ - and $\mathrm{y}$ coordinates. However, the occupancy of specific sites is quite different. Unlike the sole Y site in the Pnmaphase $\mathrm{Li}_{3} \mathrm{YCl}_{6}$, two Ho sites are determined in the $\mathrm{Li}-\mathrm{Ho}-\mathrm{Cl}$ structure where a small amount of Ho shares with the Li2 site (Table S1). While both Li sites in $\mathrm{Li}_{3} \mathrm{YCl}_{6}$ show equal occupancy of 0.75 , the refined structure of $\mathrm{Li}-\mathrm{Ho}-\mathrm{Cl}$ indicates full occupancy at Li $8 d 1$ but more vacancy at $8 d 2$.

Both Li-Ho-Cl orthorhombic and trigonal structures are built up by the $h c p$ anion stacking, forming octahedral of six $\mathrm{Cl}^{-}$with central $\mathrm{Ho}^{3+}, \mathrm{Li}^{+}$, or vacancy. The two phases differ in their arrangement of the cations (Fig. 2a-c). In the orthorhombic Pnma structure, taking $\mathrm{Li}_{2.73} \mathrm{Ho}_{1.09} \mathrm{Cl}_{6}(x=0.09)$ sample as example, the unit cell has three octahedral sites: $4 c, 8 d 1$ and $8 d 2$ (Table S1, Fig. 2b). The $4 c$ octahedral site is occupied only by Ho ion with an occupancy parameter of $0.947(0)$. The $8 d 1$ octahedral site is fully occupied by Li ion. The $8 d 2$ octahedral site is occupied by Ho and Li ions with occupancy parameters of $0.202(6)$ and $0.093(2)$, respectively. The $\mathrm{Li} / \mathrm{Ho}$ ratio is then $2.42: 1.13$, which is very close to the stoichiometric ratio of 2.5:1. Each $\mathrm{HoCl}_{6}{ }^{3-}$ octahedron is surrounded by three edge-sharing $\mathrm{LiCl}_{6}{ }^{5-}$ octahedra with a short Ho-Li distance (Fig. 2d, e). It is interesting to note that the orthorhombic structure 
can only be obtained within certain limits of $x$ in $\mathrm{Li}_{3-3 x} \mathrm{Ho}_{1+x} \mathrm{Cl}_{6}$ SSEs $(0.04<x \leq 0.2)$. Compared to stoichiometric $\mathrm{Li}_{3} \mathrm{HoCl}_{6}$, the orthorhombic phase of $\mathrm{Li}_{3}-3 x \mathrm{Ho}_{1+x} \mathrm{Cl}_{6}(0.04 \leq x \leq 0.2)$ can also be regarded as a Ho-rich structure due to the doped amount of $\mathrm{Li}^{+}$by $\mathrm{Ho}^{3+}$, which leads to the introduction of more vacancies in the cation sub-lattice. Thus, even if they share a similar basic orthorhombic structure, the $\mathrm{Ho}^{3+}, \mathrm{Li}^{+}$, and vacancy occupation in $\mathrm{Li}_{3}-3 x \mathrm{Ho}_{1+x} \mathrm{Cl}_{6}(0.04 \leq \mathrm{x} \leq 0.2)$ is slightly different from that of stoichiometric $\mathrm{Li}_{3} \mathrm{HoCl}_{6}$. For $\mathrm{Li}_{3} \mathrm{HoCl}_{6}$ having a trigonal structure, there are three $\mathrm{Ho}$ sites (Fig. 2C). One is fully occupied (Ho1, Wyckoff $1 \mathrm{a}$ site) and the other two are partially occupied. There are two Li sites, the fully occupied Li1 layer (Wyckoff $6 g$ site) and half occupied Li2 layer (Wyckoff $6 d$ site) along the $c$ axis. As exhibited in Fig. $1 \mathrm{~g}$ and $1 \mathrm{~h}$, each $\mathrm{HoCl}_{6}{ }^{3-}$ octahedron is surrounded by six edge-shared $\mathrm{LiCl}_{6}{ }^{5-}$ octahedra, forming a honeycomb lattice in the $a b$ plane. The trigonal structure contains infinite chains of face-sharing $\mathrm{HoCl}_{6}{ }^{3-}$ octahedra in the [001] direction. The local structure of the $\mathrm{HoCl}_{6}{ }^{3-}$ octahedron is also different between the orthorhombic and trigonal structures of $\mathrm{Li}_{3} \mathrm{HoCl}_{6}$ (Fig. $1 \mathrm{f}$ and i). Specifically, in orthorhombic $\mathrm{Li}_{3} \mathrm{HoCl}_{6}$, the asymmetric local environment induces a distorted $\mathrm{Cl}$ arrangement around $\mathrm{Ho}$ (Fig. 1f).

Holmium $L_{3}$ edge $X$-ray absorption fine structure (XAFS) was employed to reveal the detailed structure of the Li-Ho-Cl SSEs with different compositions. The experimental XAFS results of $\mathrm{Li}_{3}-3 x \mathrm{Ho}_{1+x} \mathrm{Cl}_{6}(x=$ $-0.14,0,0.09,0.2$, and 0.5$)$ were compared in Figure S4. The spectra of $\mathrm{Li}_{1.5} \mathrm{Ho}_{1.5} \mathrm{Cl}_{6}(x=0.5)$ and $\mathrm{Li}_{2.4} \mathrm{Ho}_{1.2} \mathrm{Cl}_{6}(x=0.2)$ share similar characteristic features, which are slightly different from that of the other three compositions. The difference should be due to the existence of a $\mathrm{HoCl}_{3}$ impurity phase in $\mathrm{Li}_{1.5} \mathrm{Ho}_{1.5} \mathrm{Cl}_{6}(x=0.5)$ and $\mathrm{Li}_{2.4} \mathrm{Ho}_{1.2} \mathrm{Cl}_{6}(x=0.2)$ samples. Moreover, the detailed difference of the XAFS results between Pnma and $P-3 m 1$ phase of $\mathrm{Li}_{3-3 x} \mathrm{Ho}_{1+x} \mathrm{Cl}_{6}$ has been provided in Fig. 3a. There are four different characteristic peaks in the X-ray absorption near edge structure (XANES) spectra. The characteristic peaks are marked as a, b, c, and d for convenience. In fact, there is not much difference in the Ho local environment between $P n m a$ and $P-3 m 1$ phase. They have the same chemical state and the similar first shell ( $\mathrm{HoCl}_{6}{ }^{3-}$, Figs. 2f, 2i, and $3 \mathrm{f}$ bright green points close to $\mathrm{Ho}$ ). The difference comes from a slight distortion of the $\mathrm{HoCl}_{6}{ }^{3-}$ octahedron in Pnma phase and different arrangement of cations in the second shell which is related to the Li and vacancy sites (Fig. 3f, dark green points). XAFS is very sensitive to subtle structural changes. We set $P n m a$ and $P-3 m 1$ phases of $\mathrm{Li}_{3} \mathrm{HoCl}_{6}$ as the initial models for the curve fitting of the $\mathrm{Li}_{2.73} \mathrm{Ho}_{1.09} \mathrm{Cl}_{6}(x=0.09)$ spectrum. As a result, a much better fit using the Pnma model than the $P-3 m 1$ model, which further confirms the new structure of $\mathrm{Li}_{3}{ }_{3 x} \mathrm{Ho}_{1+x} \mathrm{Cl}_{6}$. The XAFS models were further developed based on $\mathrm{Li}_{2.73} \mathrm{Ho}_{1.09} \mathrm{Cl}_{6}(x=0.09)$ with Pnma structure. Figure $3 \mathrm{~b}-\mathrm{d}$ show the overall $k \chi(k)$, back Fourier transform (BFT) filtered $k \chi(k)$ for the 1st shell FT, and BFT filtered $k \chi(k)$ for the $2 \mathrm{nd}$ shell FT of the $\mathrm{Li}_{2.73} \mathrm{Ho}_{1.09} \mathrm{Cl}_{6}(x=0.09, P n m a)$ sample, respectively. Close agreement is achieved between the experimental data and Feff modeling ${ }^{27}$ for the Ho centered spherical cluster with a radius of $\mathrm{R}=6 \AA$ as presented in Fig. $3 f$, thus the initial Feff modeling well supports the Ho local structural environment in the $\mathrm{Li}_{2.73} \mathrm{Ho}_{1.09} \mathrm{Cl}_{6}(x=0.09)$ with Pnma structure. Guided by the theoretical Pnma structure of $\mathrm{Li}_{3} \mathrm{HoCl}_{6}$, Ho centered spherical cluster was developed up to $5.5 \AA$, covering Ho local structure 
environment up to the 2nd FT peak (latched data range, inset of Figure S5). Feff modeling of each Hocentered atomic pairs was performed for scattering phase and magnitude. A five-path structure model for $\mathrm{R}$ space curve fitting was developed with scattering paths from corresponding coordination shells predicted by the theoretical Pnma structure of $\mathrm{Li}_{3} \mathrm{HoCl}_{6}$ to be degenerated into 5 individual scattering paths (Table S2). The calculation predicted coordination number (CN) and bond distances (averaged from all paths of those corresponding shells) were used to guide the R space curve fitting ${ }^{28}$. Table S2 shows the comparison between $\mathrm{R}$ space curve fitting result and theoretical Pnma model in structure parameters. Figures S6, 7 compared the experimental data and Feff modeling in FT (mag \& im part of FT; total and individual paths) and $k^{3} \chi(k)$ (total and individual paths). It can be concluded that $\mathrm{R}$ space curve fitting is well consistent with the initial Feff modeling. In addition, Finite Difference Method for Near Edge Structure (FDMNES) modeling ${ }^{28}$ was performed to develop the corresponding theoretical XANES based on the same cluster (Fig. 3f). Comparison is made between the modeling and experimental data in XANES (Fig. 3e) and their first derivative spectra (inset of Fig. 3e), revealing good agreement. The modeling data in $k$ space for $k \chi(k)$ (Figure S8) is also consistent with the initial Feff modeling (Fig. 3b). Thus, the Ho occupation at octahedral sites of the $\mathrm{Li}_{2.73} \mathrm{Ho}_{1.09} \mathrm{Cl}_{6}$ framework was proven by the initial Feff modeling, R space curve fitting, and XANES theoretical modeling.

Ionic conductivities of the cold-pressed $\mathrm{Li}_{3}-3 x \mathrm{Ho}_{1+x} \mathrm{Cl}_{6}$ SSEs were measured by temperature-dependent alternating-current (AC) impedance using a carbon/SSE/carbon cell. The conductivity isotherms as a function of frequency $v$ of the $\mathrm{Li}_{2.73} \mathrm{Ho}_{1.09} \mathrm{Cl}_{6}$ SSE are presented in Fig. 4a. The conductivity plateau at $25^{\circ} \mathrm{C}$ corresponds to $\sim 1.3 \times 10^{-3} \mathrm{~S} \mathrm{~cm}^{-1}$ is associated with the long-range ion transport. The 3D ionic transport in the structure of $\mathrm{Li}_{2.73} \mathrm{Ho}_{1.09} \mathrm{Cl}_{6}$ SSE is reflected by the dispersive regime at higher frequency at $-15^{\circ} \mathrm{C}$ with a $K$ value of 0.67 according to the Jonscher's power law ${ }^{29,30}\left(\sigma(v) \propto v^{k}\right)$, as shown in Fig. 4a. Figure $4 \mathrm{~b}$ shows the comparison of representative Nyquist plots at $25^{\circ} \mathrm{C}$ for the $\mathrm{Li}_{2.73} \mathrm{Ho}_{1.09} \mathrm{Cl}_{6}$ (Pnma phase) and the $\mathrm{Li}_{3} \mathrm{HoCl}_{6}$ ( $P-3 m 1$ phase) SSEs. The equivalent circuit is presented in Fig. $4 \mathrm{~b}$, which consists of one parallel constant phase element (CPE)/resistor (R) in series with a CPE. The ideality CPE for the parallel combination $\mathrm{CPE} / \mathrm{R}$ can be concluded from the estimated ideality factor a of 0.876 and 0.868 for the $\mathrm{Li}_{2.73} \mathrm{Ho}_{1.09} \mathrm{Cl}_{6}$ and $\mathrm{Li}_{3} \mathrm{HoCl}_{6} \mathrm{SSEs}$, respectively ${ }^{31}$. Moreover, the bulk transport characteristics of these SSEs can be reflected from their geometric capacitance $\mathrm{C}$ values $\left(49.58 \mathrm{pF} \mathrm{cm}^{-2}\right.$ for $\mathrm{Li}_{2.73} \mathrm{Ho}_{1.09} \mathrm{Cl}_{6}$ and $47.83 \mathrm{pF} \mathrm{cm}-2$ for $\left.\mathrm{Li}_{3} \mathrm{HoCl}_{6}\right)^{32}$. Arrhenius plots of all samples of $\mathrm{Li}_{3}-3 x \mathrm{Ho}_{1+x} \mathrm{Cl}_{6}$ are shown in Fig. 4c, and the extracted activation energies $\left(E_{a}\right)$ with RT ionic conductivities in $\mathrm{Li}_{3}-$ ${ }_{3 x} \mathrm{Ho}_{1+x} \mathrm{Cl}_{6}$ SSEs are presented in Fig. $4 \mathrm{~d}$. For the Pnma structures $(0.04<x \leq 0.2)$, the RT ionic conductivities gradually increase with decreasing $x$, where the maximum ionic conductivity of $1.3 \times 10^{-3}$ $\mathrm{S} \mathrm{cm}^{-1}$ is obtained at $x=0.09$. In contrast, the ionic conductivity decreases dramatically when decreases further to $x=0.02$. As aforementioned, $\mathrm{Li}_{3-3 x} \mathrm{Ho}_{1+x} \mathrm{Cl}_{6}$ changes from Pnma to $P-3 m 1$ when $x \leq 0.02$. $\mathrm{Li}_{3} \mathrm{HoCl}_{6}(P-3 m 1)$ exhibits a RT $\mathrm{Li}^{+}$conductivity of $2.9 \times 10^{-4} \mathrm{~S} \mathrm{~cm}^{-1}$ (the conductivity isotherms are shown in Figure S9). The further decrease of ionic conductivity along with the decreasing of $x$ value could be due to the formation of a $\mathrm{LiCl}$ impurity phase, which is also present in the XRD results. Moreover, the 
activation energies of the $\mathrm{Li}_{3-3 x} \mathrm{Ho}_{1+x} \mathrm{Cl}_{6}$ SSEs present the opposite trend (Fig. 4d). An activation energy below $0.4 \mathrm{eV}$ is achieved for $\mathrm{Li}_{3}-{ }_{3 x} \mathrm{Ho}_{1+x} \mathrm{Cl}_{6}$ SSEs with the Pnma phase $(0.02<x \leq 0.2)$. The minimum activation energy occurs at $x=0.09$, which is consistent with the highest ionic conductivity of the resulting material. When $x$ is lower than 0.02 , where $\mathrm{Li}_{3-3 x} \mathrm{Ho}_{1+x} \mathrm{Cl}_{6}$ has the $P-3 m 1$ phase, the activation energy notably increases with decreasing $x$. This indicates that the cation arrangement of the Pnma symmetry supports a lower activation energy for Li-ion transport as compared to $P-3 m 1$, both having the same anion sub-lattice.

The electronic conductivity of $\mathrm{Li}_{2.73} \mathrm{Ho}_{1.09} \mathrm{Cl}_{6}(x=0.09)$ SSE was measured by chronoamperometry. Figure $\mathrm{S} 10$ shows the current response for $\mathrm{Li}_{2.73} \mathrm{Ho}_{1.09} \mathrm{Cl}_{6}(x=0.09)$, with the initial response for both $\mathrm{Li}^{+}$and electron transport and the steady-state response for electron transport. The electronic conductivity of $\mathrm{Li}_{2.73} \mathrm{Ho}_{1.09} \mathrm{Cl}_{6}(x=0.09)$ is less than $1 \times 10^{-9} \mathrm{~S} \mathrm{~cm}^{-1}$ as calculated by Ohm's law at the voltage range from 0.1 to $0.4 \mathrm{~V}$. At the same time, the stability of $\mathrm{Li}_{3}-3 x \mathrm{Ho}_{1+x} \mathrm{Cl}_{6}$ SSEs in dry air was evaluated by thermo gravimetric analysis, differential scanning calorimetry (Figure S11) test, and XRD measurements (Figure S12,13) after exposure in a lithium battery dry room for $24 \mathrm{~h}$. The results confirm that $\mathrm{Li}_{3}$ ${ }_{3 x} \mathrm{Ho}_{1+x} \mathrm{Cl}_{6}$ SSEs are stable in dry air and can be exposed for hours in the lithium battery dry room, which facilitates practical application.

In order to figure out whether the phase transition from a trigonal-to-orthorhombic is unique in the $\mathrm{Li}-\mathrm{Ho}-\mathrm{Cl}$ system or universal in other kinds of metal chloride electrolytes, a similar synthesis process of all Li$\mathrm{M}(\mathrm{III})-\mathrm{Cl}$ component with a previously reported $P-3 m 1$ space group has been performed. As shown in Figures S14-19, for the compositions of $x>0.04$, a trigonal-to-orthorhombic phase transition is induced in all Li-M(III)-Cl (M = Y, Er, Dy, Tm) with a P-3m1 space group except $\mathrm{Li}-\mathrm{Tb}-\mathrm{Cl}$ component. The metastable orthorhombic structure of $\mathrm{Li}_{3} \mathrm{YCl}_{6}$ have been previously eported ${ }^{6,18}$. While for other $\mathrm{Li}-\mathrm{M}(\mathrm{III})-\mathrm{Cl}(\mathrm{M}=\mathrm{Ho}, \mathrm{Er}$, Dy, Tm), this is the first time to achieve its orthorhombic phase, which not only extends its contents and application but also makes more clear understanding of the chemistry and structure formation of ternary rare earth chloride. These trigonal-to-orthorhombic phase transition by changing the ratio of Li and M(III) cations indicates that not only the average metal radius plays a role, but also the average cation size (including both $\mathrm{Li}^{+}$and $\mathrm{M}^{3+}$ ). At the same time, the increased conductivity going from the trigonal to the orthorhombic phase can be found in all $\mathrm{Li}_{3}-3 x \mathrm{M}_{1+x} \mathrm{Cl}_{6}(-0.14<x \leq 0.5)$ SSEs. As shown in Table 1 , a high ionic conductivity up to $7 \times 10^{-4} \mathrm{~S} \mathrm{~cm}^{-1}$ at room temperature can be achieved in orthorhombic phase $\mathrm{Li}_{2.73} \mathrm{Y}_{1.09} \mathrm{Cl}_{6}(x=0.09)$, which is more than 12 times higher than that of the trigonal phase $\mathrm{Li}_{3} \mathrm{YCl}_{6}(x=0)$. The ionic conductivity of the new orthorhombic phase of $\mathrm{Li}_{2.73} \mathrm{Er}_{1.09} \mathrm{Cl}_{6}(x=0.09)$ is also seven times higher than that of trigonal phase of $\mathrm{Li}_{3} \mathrm{ErCl}_{6}(x=0)$ at room temperature $\left(6.4 \mathrm{vs} .0 .9 \times 10^{-4} \mathrm{~S} \mathrm{~cm}^{-1}\right)$. Orthorhombic phase $\mathrm{Li}_{2.73} \mathrm{Dy}_{1.09} \mathrm{Cl}_{6}(x=0.09)$ can reach to $9 \times 10^{-4} \mathrm{~S} \mathrm{~cm}^{-1}$ at room temperature, while it can only achieve about $1.2 \times 10^{-4} \mathrm{~S} \mathrm{~cm}^{-1}$ at room temperature in trigonal phase of $\mathrm{Li}_{3} \mathrm{DyCl}_{6}(x=0)$. For $\mathrm{Li}_{3-3 x} \mathrm{Tm}_{1+x} \mathrm{Cl}_{6}$ SSEs, the orthorhombic phase structure also have a higher ionic conductivity at room temperature than that of trigonal phase $\left(8.9 \mathrm{vs} .1 .1 \times 10^{-4} \mathrm{~S} \mathrm{~cm}^{-1}\right)$. In general, around one order of 
magnitude different in ionic conductivities is observed in the isostructural $\mathrm{Li}-\mathrm{Dy}-\mathrm{Cl}, \mathrm{Li}-\mathrm{Y}-\mathrm{Cl}, \mathrm{Li}-\mathrm{Er}-\mathrm{Cl}$, and $\mathrm{Li}$ $\mathrm{Tm}-\mathrm{Cl}$ compositions. As a result, lots of new ternary metal chloride superionic conductors have been found and reported here. Moreover, the similar structural transition process in many kinds of $\mathrm{Li}_{3}$ ${ }_{3 x} \mathrm{M}_{1+x} \mathrm{Cl}_{6}(-0.14<x \leq 0.5)$ SSEs indicates a general phenomenon, which can be used to explore and achieve many new materials with unknown phase structures.

Table 1

$\mathrm{Li}^{+}$conductivity at room temperature of $\mathrm{Li}_{3-3 x} \mathrm{M}_{1+x} \mathrm{Cl}_{6}$ SSEs with different $\mathrm{M}$ and phase structure .

\begin{tabular}{|c|c|c|c|c|}
\hline Electrolytes & Component & $\begin{array}{l}\text { Phase } \\
\text { Structure }\end{array}$ & $\begin{array}{l}\mathrm{Li}^{+} \text {Conductivity at } \mathrm{RT}\left(\times 10^{-3} \mathrm{~S}\right. \\
\left.\mathrm{cm}^{-1}\right)\end{array}$ & $\begin{array}{l}\text { Activation Energy } \\
(\mathrm{eV})\end{array}$ \\
\hline \multirow[t]{2}{*}{$\begin{array}{l}\mathrm{Li}_{3}- \\
{ }_{3 x} \mathrm{~Tb}_{1+x} \mathrm{Cl}_{6}\end{array}$} & $x=0$ & $\begin{array}{l}P-3 m 1 \\
\text { phase }\end{array}$ & 0.22 & 0.39 \\
\hline & $x=0.09$ & $\begin{array}{l}\text { Unknown } \\
\text { phase }\end{array}$ & 0.0000062 & 0.53 \\
\hline \multirow[t]{2}{*}{$\begin{array}{l}\mathrm{Li}_{3-} \\
{ }_{3 x} \mathrm{Dy}_{1+\mathrm{x}} \mathrm{Cl}_{6}\end{array}$} & $x=0$ & $\begin{array}{l}P-3 m 1 \\
\text { phase }\end{array}$ & 0.12 & 0.42 \\
\hline & $x=0.09$ & Pnma phase & 0.90 & 0.38 \\
\hline \multirow[t]{2}{*}{$\begin{array}{l}\mathrm{Li}_{3}- \\
{ }_{3 x} \mathrm{Ho}_{1+x} \mathrm{Cl}_{6}\end{array}$} & $x=0$ & $\begin{array}{l}P-3 m 1 \\
\text { phase }\end{array}$ & 0.29 & 0.45 \\
\hline & $x=0.09$ & Pnma phase & 1.30 & 0.39 \\
\hline \multirow[t]{2}{*}{$\begin{array}{l}\mathrm{Li}_{3-} \\
3 x \\
\mathrm{Y}_{1+x} \\
\mathrm{Cl}_{6}\end{array}$} & $x=0$ & $\begin{array}{l}P-3 m 1 \\
\text { phase }\end{array}$ & 0.059 & 0.47 \\
\hline & $x=0.09$ & Pnma phase & 0.70 & 0.39 \\
\hline \multirow[t]{2}{*}{$\begin{array}{l}\mathrm{Li}_{3}- \\
{ }_{3 x} \mathrm{Er}_{1+x} \mathrm{Cl}_{6}\end{array}$} & $x=0$ & $\begin{array}{l}P-3 m 1 \\
\text { phase }\end{array}$ & 0.090 & 0.47 \\
\hline & $x=0.09$ & Pnma phase & 0.64 & 0.40 \\
\hline \multirow[t]{2}{*}{$\begin{array}{l}\mathrm{Li}_{3}- \\
{ }_{3 x} \mathrm{Tm}_{1+x} \mathrm{Cl}_{6}\end{array}$} & $x=0$ & $\begin{array}{l}P-3 m 1 \\
\text { phase }\end{array}$ & 0.11 & 0.41 \\
\hline & $x=0.09$ & Pnma phase & 0.89 & 0.38 \\
\hline TOC & & & & \\
\hline
\end{tabular}

To understand the difference in ionic conductivities between the two structures, both phases were simulated by $a b$ initio Molecular Dynamics. The Pnma phase shows higher long-range diffusion, as illustrated by the mean square displacement (Fig. 5a), as well as from the offset of the slopes in the plot illustrating the Arrhenius behaviour (Fig. 5b). The activation energies extracted from the slope of the Arrhenius plot are almost similar, which have a slightly difference in the experimental observations 
(Fig. 4). To further investigate the reason for the higher conductivity we consider the equation for the diffusion coefficient:

$$
D=g f v^{0} a^{2} \exp \left(\frac{E_{a}}{k_{b} T}\right)=D_{0} \exp \left(\frac{E_{a}}{k_{b} T}\right)
$$

Here, $g$ is the geometrical factor, $f$ the correlation factor, $v^{0}$ the attempt frequency, and $a$ the jump distance, which can all be summarized into the preexponential factor $D_{0}$. The geometrical factor describes the effect of a porous network on diffusion. The correlation factor describes the percentage of back and forth movements of atoms between sites, and is defined as

$$
f=\frac{D_{\text {Tracer }}}{D_{\text {jump }}}
$$

where $D_{\text {Tracer }}$ is the tracer diffusion coefficient and $D_{\text {jump }}$ the jump diffusion coefficient.

The attempt frequency $v_{0}$ and amplitude of the $\mathrm{Li}^{+}$ions were extracted by the Fourier transform of the diffusion paths, as described elsewhere ${ }^{33}$. Both the frequencies and the amplitudes are similar in both phases. The increase in ionic conductivity is therefore not due to an increase in attempt frequency. Using the same algorithm for the attempt frequency, the $\mathrm{Cl}$ vibrations were analyzed as well. As can be expected considering the structural similarity of the $h c p$ stacked chlorine atoms, the $\mathrm{Cl}$ vibrational amplitudes and frequencies are also similar. (Figure S20). The jump distance $a$ can be approximated by the distance between the different Wyckhoff sites. The $a$ values are similar for both phases, around $3.1 \AA$

Hence, the difference observed in $D_{0}$ has to arise either from the geometrical factor or the correlation factor. It is therefore interesting to compare the jump rates between sites and the long-range diffusion path. Figures $5 \mathrm{c}$ and d illustrate the jumps between different $\mathrm{Li}$ sites. The blue circles are the Li sites, and the different sizes of the blue circles represent the occupancy of the site. The red lines represent jumps that occurred, with the thickness of the line indicating the frequency of the jump occurred. The green trajectories belong to the Ho atoms, and the Wyckoff sites are included. For the Pnma phase at $500 \mathrm{~K}$ (Figure 5c), there is a clear long-range diffusion path along the z-direction between the Wyckoff $8 d 1$ and $8 d 2$ sites. Even though jumps between the $8 d 1$ and $8 d 2$ sites are also possible in the $x y$-plane, these jumps only start occurring at $600 \mathrm{~K}$ (Figure S21). This indicates that the jumps along the $z$-direction have a lower activation energy than cross-plane jumps, thus indicating that the high conductivity is mainly due to these one-dimensional diffusion pathways. For the $P$ - $3 m 1$ phase, the jumps in the $z$-direction between the $6 h$ and $6 g$ sites are the most frequently occurring jumps (Figure $5 \mathrm{~d}$ and S22). Though in principle, the pathway along the $z$-direction is also possible, the clear long-range path as in Pnma is not present. Considering the structures, this is caused by the different Ho arrangements, leading to a different local structure which can be less favourable for jump processes. A different initial arrangement of Ho on the sites would probably lead to different diffusion pathways, but this was not investigated in the scope of 
this report. The effect of $\mathrm{M}(\mathrm{III})$ site occupancy in the $P-3 m 1$ phase has been previously studied for the $P$ $3 m 1$ phase of $\mathrm{Li}_{3} \mathrm{YCl}_{6}$ and $\mathrm{Li}_{3} \mathrm{ErCl}_{6}{ }^{6,34}$. It was found that the structures with more frequently occurring M1 and M3 distances (hence, a higher joint occupancy of neighbouring M1 and M3 sites), the diffusivity increases. This was explained by a continuous diffusion path in the $z-y$ plane passing through one of the free tetrahedral sites. The present results indicate that the facile diffusion in the $z$-direction in the Pnma phase is more favorable for achieving high conductivities.

As presented in Figure 6a, the $\mathrm{Li}_{2.73} \mathrm{Ho}_{1.09} \mathrm{Cl}_{6}(x=0.09) \mathrm{SSE}$ is predicted to have a wide electrochemical stability window of $0.64-4.25 \mathrm{~V}$ by using the established scheme based on the Materials Project ${ }^{35}$. In the calculation process, $\mathrm{HoCl}_{3}$ and $\mathrm{Cl}_{2}$ were set as the oxidation products and $\mathrm{Ho}_{5} \mathrm{Cl}_{11}$ and $\mathrm{LiCl}$ are considered as the reduction products. The wide electrochemical stability window of $\mathrm{Li}_{2.73} \mathrm{Ho}_{1.09} \mathrm{Cl}_{6} \mathrm{SSE}$ is similar to the previous result of $\mathrm{Li}_{3} \mathrm{HoCl}_{6}$ SSEs with $P-3 m 1$ structure ${ }^{11}$. Since the electrochemical windows of halide SSEs is mainly dominated by the oxidation voltage of the halogen anion and reduction voltages of the metal cation, the synthesized $\mathrm{Li}_{2.73} \mathrm{Ho}_{1.09} \mathrm{Cl}_{6}(x=0.09) \mathrm{SSE}$ is also estimated to possess a similarly wide electrochemical window. Moreover, such wide electrochemical stability window can be further reflected from the cyclic voltammetry (CV) curve of $\mathrm{Li} / \mathrm{Li}_{7} \mathrm{P}_{3} \mathrm{~S}_{11} / \mathrm{Li}_{2.73} \mathrm{Ho}_{1.09} \mathrm{Cl}_{6} / \mathrm{Li}_{2.73} \mathrm{Ho}_{1.09} \mathrm{Cl}_{6}{ }^{-}$ Au cell (Figure 6b) with the mixture of $\mathrm{Li}_{2.73} \mathrm{Ho}_{1.09} \mathrm{Cl}_{6}$ and $\mathrm{Au}$ (1:1, mass ratio) as active electrode. The long-term stability of $\mathrm{Li}_{2.73} \mathrm{Ho}_{1.09} \mathrm{Cl}_{6}$ toward bare $\mathrm{Li}$ metal was evaluated by galvanostatic cycling at 0.1 $\mathrm{mA} \mathrm{cm}{ }^{-2}\left(0.5 \mathrm{mAh} \mathrm{cm}^{-2}\right)$ at room temperature, as shown in Figure $6 \mathrm{c}$. The symmetric $\mathrm{Li} / \mathrm{Li}_{2.73} \mathrm{Ho}_{1.09} \mathrm{Cl}_{6} / \mathrm{Li}$ cell shows a steady overpotential of $580 \mathrm{mV}$ in the initial cycles, which gradually decreases to $\sim 50 \mathrm{mV}$ over $900 \mathrm{~h}$. The reduced overpotential might be due to the increased electroactive surface area of the Li metal caused by dendrite growth in the grain boundary of SSEs layer, thus causing the localized current density to decrease, with a consequential decrease in overpotential.

The performance of $\mathrm{Li}_{2.73} \mathrm{Ho}_{1.09} \mathrm{Cl}_{6}$ as SSE in ASSLBs is demonstrated with a composite cathode with $\mathrm{LiNi}_{0.8} \mathrm{Mn}_{0.1} \mathrm{Co}_{0.1} \mathrm{O}_{2}$ (NMC811) as active materials ( $\mathrm{NMC811/Li}{ }_{2.73} \mathrm{Ho}_{1.09} \mathrm{Cl}_{6}=7: 3$ $\mathrm{w} / \mathrm{w}), \mathrm{Li}_{2.73} \mathrm{Ho}_{1.09} \mathrm{Cl}_{6}$ as the SSE layer, and In as anode. The EIS of the assembled ASSLB remained almost unchanged within $24 \mathrm{~h}$ (Figure S23), suggesting a good chemical stability between the oxide cathode material and the halide SSE. The ASSLBs were charged and discharged at different current densities in the voltage range of 1.90-3.70 V vs $\mathrm{Li}^{+} / \mathrm{Li}-\ln \left(2.50-4.30 \mathrm{~V} v s \mathrm{Li}^{+} / \mathrm{Li}\right)$. Figure 7a presents the charge/discharge profiles of the ASSLB operated at $25^{\circ} \mathrm{C}$ and $-10{ }^{\circ} \mathrm{C}$. At $25^{\circ} \mathrm{C}$, the initial charge/discharge capacities are 209 and $172 \mathrm{mAh} \mathrm{g}^{-1}(0.1 \mathrm{C})$, corresponding to an initial Coulombic efficiency of $82.3 \%$. At $-10{ }^{\circ} \mathrm{C}$, the NMC811/ $/ \mathrm{Li}_{2.73} \mathrm{Ho}_{1.09} \mathrm{Cl}_{6} / \mathrm{In}$ ASSLB exhibits an initial Coulombic efficiency of $79.4 \%$ and a reversible capacity of $142 \mathrm{mAh} \mathrm{g}^{-1}$ at $0.025 \mathrm{C}$, which might be caused by the sluggish $\mathrm{Li}^{+}$migration within the cathode layer at lower temperatures. However, the

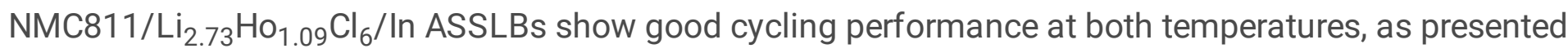
in Figure $7 \mathrm{~b}$ and Figure S24, with specific capacities of $125.5 \mathrm{mAh} \mathrm{g}^{-1}$ and $90 \mathrm{mAh} \mathrm{g}^{-1}$ remaining after 180 cycles at $25^{\circ} \mathrm{C}$ and 100 cycles at $-10^{\circ} \mathrm{C}$. The typical delithiation/lithiation behaviour of NMC811 is clearly visible in the differential capacity curves (Figure 7c). Three pairs of redox peaks are observed, 
corresponding to the phase transitions from hexagonal to monoclinic $(\mathrm{H} 1 \rightarrow \mathrm{M})$, monoclinic to hexagonal $(\mathrm{M} \rightarrow \mathrm{H} 2)$, and hexagonal to hexagonal $(\mathrm{H} 2 \rightarrow \mathrm{H} 3)$. The high initial Coulombic efficiency and lack of redox reactions attributed to the $\mathrm{Li}_{2.73} \mathrm{Ho}_{1.09} \mathrm{Cl}_{6}$ SSE indicate that $\mathrm{Li}_{2.73} \mathrm{Ho}_{1.09} \mathrm{Cl}_{6}$ is stable towards NMC811 within the applied voltage range. The rate capabilities at different current densities ranging from $100 \mathrm{~mA}$ $\mathrm{g}^{-1}$ to $1000 \mathrm{~mA} \mathrm{~g}^{-1}(0.1 \mathrm{C}$ to $1 \mathrm{C})$ at $25^{\circ} \mathrm{C}$ are displayed in Figure $7 \mathrm{~d}$. The capacity gradually decreases along with an increase of current density, with $98 \mathrm{mAh} \mathrm{g}^{-1}$ achieved at $1 \mathrm{C}(58 \%$ capacity retention of that at $0.1 \mathrm{C}$ ). Moreover, the capacity can be recovered upon returning to the initial $0.1 \mathrm{C}$ rate.

To monitor the interfacial resistance contributions, EIS spectra were measured at different state-of-charge (SOC) and state-of-discharge (SOD) during the $3^{\text {rd }}$ charge/discharge process (Figure 7e, voltage evolution

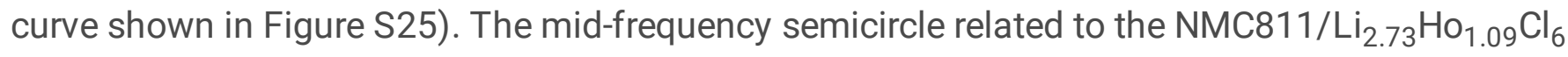
interfacial resistance increased slightly during the charging process and decreased again during the discharging process. The change in the interfacial resistance might be caused by the mild volume shrinkage of NMC811 during delithiation and corresponding volume recovery once lithiated ${ }^{36}$. To further exclude the possible decomposition of $\mathrm{Li}_{2.73} \mathrm{Ho}_{1.09} \mathrm{Cl}_{6}$ or chemical reaction between NMC811 and $\mathrm{Li}_{2.73} \mathrm{Ho}_{1.09} \mathrm{Cl}_{6}$ during cycling, synchrotron-based high energy $\mathrm{X}$-ray photoelectron spectroscopy (HEXPS) and XANES analyses of NMC811/ $\mathrm{Li}_{2.73} \mathrm{Ho}_{1.09} \mathrm{Cl}_{6}$ composites at different states were conducted. As shown in Figures 7f, $g$ and Figure S26, no matter whether the cell was fully charged/discharged at the $1^{\text {st }}$ cycle or fully discharged after 50 cycles, the $\mathrm{Ho} 4 \mathrm{~d}$ and $\mathrm{Cl} 1 \mathrm{~s}$ spectra of NMC811/Li $2.73 \mathrm{Ho}_{1.09} \mathrm{Cl}_{6}$ composite obtained with a photon energy of $3 \mathrm{keV}$ are similar, with typical peaks at $\sim 160 \mathrm{eV}$ and $2815 \mathrm{eV}$ observed, respectively. Even when further increasing the photon energy to $6 \mathrm{keV}$, which can provide chemical information from deeper in the $\mathrm{NMC} 811 / \mathrm{Li}_{2.73} \mathrm{Ho}_{1.09} \mathrm{Cl}_{6}$ composite, little change in both position and shape for the obtained $\mathrm{Ho} 4 \mathrm{~d}$ and $\mathrm{Cl} 1 \mathrm{~s}$ spectra was observed (Figure S26), demonstrating that the chemical state of $\mathrm{Ho}$ and $\mathrm{Cl}$ on the surface and inner part

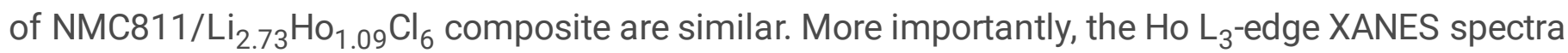
(Figure 7h) and the corresponded first derivative spectra (Figure 7i) of the NMC811/ $\mathrm{Li}_{2.73} \mathrm{Ho}_{1.09} \mathrm{Cl}_{6}$ composite at different charge/discharge states also showed no obvious change. Therefore, it can be concluded that there is a stable interface between $\mathrm{NMC} 811$ and $\mathrm{Li}_{2.73} \mathrm{Ho}_{1.09} \mathrm{Cl}_{6} \mathrm{SSE}$ regardless of the static physical contact or during charge/discharge cycling process.

\section{Conclusion}

In summary, the ternary metal chloride solid electrolyte series of $\mathrm{Li}_{3}-3 x \mathrm{M}_{1+x} \mathrm{Cl}_{6}(-0.14<x \leq 0.2, \mathrm{M}=\mathrm{Tb}$, Dy, $\mathrm{Ho}, \mathrm{Y}, \mathrm{Er}, \mathrm{Tm})$ reveal a phase transition from trigonal $(P-3 m 1)$ to orthorhombic (Pnma) upon increasing $x$ values for M-rich environments. Both $P-3 m 1$ and Pnma structures consist of $h c p$ framework of $\mathrm{Cl}^{-}$anions but differ in their cations (including $\mathrm{Li}^{+}$and $\mathrm{M}^{3+}$ ) arrangement. Using $\mathrm{Li}_{3-3 x} \mathrm{Ho}_{1+x} \mathrm{Cl}_{6}(-0.14<x \leq 0.2)$ as an example, the relationship between structure and Li-ion conductivity is revealed by temperaturedependent EIS, X-ray and neutron diffractions and $a b$ initio MD simulations. The highest $\mathrm{RT} \mathrm{Li}^{+}$ conductivity of $1.3 \times 10^{-3} \mathrm{~S} \mathrm{~cm}^{-1}$ is achieved for the orthohombic $\mathrm{Li}_{2.73} \mathrm{Ho}_{1.09} \mathrm{Cl}_{6}$, which is over four times 
higher than that of the trigonal $\mathrm{Li}_{3} \mathrm{HoCl}_{6}\left(0.3 \times 10^{-3} \mathrm{~S} \mathrm{~cm}^{-1}\right)$. About one order of magnitude difference in ionic conductivities is observed in the isostructural $\mathrm{Li}-\mathrm{Dy}-\mathrm{Cl}, \mathrm{Li}-\mathrm{Y}-\mathrm{Cl}, \mathrm{Li}-\mathrm{Er}-\mathrm{Cl}$, and $\mathrm{Li}-\mathrm{Tm}-\mathrm{Cl}$ compositions. The phase transition to Pnma triggers a significant increase in $\mathrm{Li}^{+}$diffusivity and reduces the activation energy barrier for $\mathrm{Li}^{+}$diffusion in all different $\mathrm{Li}-\mathrm{M}-\mathrm{Cl}$ systems. Considering the vast number of isomorphic structures, the synthesis strategy based on trigonal-to-orthorhombic phase transition phenomenon not only can be used to discover the fundamental chemical theories of the rare earth metal halides, but also can explore and achieve new materials with high $\mathrm{Li}^{+}$conductive. Ab initio MD simulations consistently derive a higher diffusivity and a reduce activation energy of the Pnma phase comparing to the $P-3 m 1$ phase. This is due to facile one-dimensional diffusion pathways in the z-direction, which is obstructed by the different $\mathrm{Ho}$ arrangement in the $P-3 m 1$ phase. All-solid-state batteries of $\mathrm{In} / \mathrm{Li}_{2.73} \mathrm{Ho}_{1.09} \mathrm{Cl}_{6} / \mathrm{NMC} 11$ exhibit excellent electrochemical performances at both room temperature and low temperature $\left(-10^{\circ} \mathrm{C}\right)$. This further demonstrates the applicability of this new $\mathrm{Li}_{2.73} \mathrm{Ho}_{1.09} \mathrm{Cl}_{6} \mathrm{SSE}$ with high ionic conductivity and a wide electrochemical window. These results provide guidance for the design of novel halide superionic conductors and contribute to the development of ASSLBs.

\section{Declarations}

\section{Acknowledgements}

This research was supported by Natural Sciences and Engineering Research Council of Canada (NSERC), Canada Research Chair Program (CRC), Canada Foundation for Innovation (CFI), GLABAT Solid-State Battery Inc., China Automotive Battery Research Institute Co. Ltd, Ontario Research Fund, the Canada Light Source at University of Saskatchewan (CLS), Interdisciplinary Development Initiatives (IDI) by Western University, Canada MITACS fellow, and University of Western Ontario. Financial support is greatly acknowledged from the Netherlands Organization for Scientific Research (NWO) under the VICl grant nr. 16122. We also appreciate the help of the beamline scientist of HXMA (Dr. Weifeng Chen) and SXRMB (Dr. Quanfeng Xiao) beamline at Canadian Light Source.

\section{Declaration of interests}

The authors declare no competing interests.

\section{Author contribution}

+J. Liang, E. Maas, J. Luo, and X. Li contributed equally to this work. J. Liang, J. Luo, and X. Li designed, performed the experiments on material synthesis, ionic conductivity measurement, and battery testing. $\mathrm{E}$. Maas, S. Parnell, R. Smith, and S. Ganapathy perform the XRD and neutron testing and refinement and Molecular dynamics simulations. N. Chen, K. Adair, W. Li. J. Li, Y. Hu contributed to the synchrotron XAFS and HEXPS experiments and corresponding data analysis and fitting. L. Zhang, S. Zhao, S. Lu, J. Wang, and $\mathrm{H}$. Huang participated in the discussion of the experiments. J. Liang, E. Maas, J. Luo, X. Li, and K. 
Adair prepared the manuscript. All authors discussed the results and commented on the manuscript. M. Wagemaker, and X. Sun supervised the work and organize the cooperation.

\section{References}

1. Famprikis, T.; Canepa, P.; Dawson, J. A.; Islam, M. S.; Masquelier, C. Fundamentals of Inorganic SolidState Electrolytes for Batteries. Nat. Mater. 2019, 18, 1278-1291.

2. Zhang, Z.; Shao, Y.; Lotsch, B.; Hu, Y.; Li, H.; Janek, J.; Nazar, L. F.; Nan, C.; Maier, J.; Armand, M.; Chen, L. New Horizons for Inorganic Solid State Ion Conductors. Energy Environ. Sci. 2018, 11, 1945-1976.

3. Chen, R.; Li, Q.; Yu, X.; Chen, L.; Li, H. Approaching Practically Accessible Solid-State Batteries: Stability Issues Related to Solid Electrolytes and Interfaces. Chem. Rev. 2020, 120, 6820-6877.

4. Weiss, M.; Simon, F. J.; Busche, M. R.; Nakamura, T.; Schröder, D.; Richter, F. H.; Janek, J. From Liquidto Solid-State Batteries: Ion Transfer Kinetics of Heteroionic Interfaces. Electrochem. Energy Rev. 2020, 3, 221-238.

5. Zhao, Q.; Stalin, S.; Zhao, C.; Archer, L. A. Designing Solid-State Electrolytes for Safe, Energy-Dense Batteries. Nat. Rev. Mater. 2020, 5, 229-252.

6. Li, X.; Liang, J.; Yang, X.; Adair, K.; Wang, C.; Zhao, F.; Sun, X. Progress and Perspectives of HalideBased Lithium Conductors for All-Solid-State Batteries. Energy Environ. Sci. 2020.13, 1429-1461.

7. Schlem, R.; Bernges, T.; Li, C.; Kraft, M. A.; Minafra, N. A Lattice Dynamical Approach for Finding the Lithium Superionic Conductor Li3Erl6.ACS Appl. Energy Mater. 2020, 3, 3684-3691

8. Zhang, Q.; Cao, D.; Ma, Y.; Natan, A.; Aurora, P.; Zhu, H. Sulfide-Based Solid-State Electrolytes: Synthesis, Stability, and Potential for All-Solid-State Batteries. Adv. Mater. 2019, 31, 1901131.

9. Ohno, S.; Banik, A.; Dewald, G. F.; Kraft, M. A.; Krauskopf, T.; Minafra, N.; Till, P.; Weiss, M.; Zeier, W. G. Materials Design of Ionic Conductors for Solid State Batteries. Prog. Energy 2020. 2. 022001.

10. Liu, Y.; Wang, S.; Nolan, A. M.; Ling, C.; Mo Y. "Tailoring the Cation Lattice for Chloride Lithium-lon Conductors." Adv. Energy Mater. 2020, 10, 2002356.

11. Wang, S.; Bai, Q.; Nolan, A. M.; Liu, Y.; Gong, S.; Sun, Q.; Mo, Y. Lithium Chlorides and Bromides as Promising Solid-State Chemistries for Fast lon Conductors with Good Electrochemical Stability. Angew. Chem. Int. Ed. 2019, 58, 8039-8043.

12. Zhu, Y.; Mo, Y. Materials Design Principles for Air-Stable Lithium/Sodium Solid Electrolytes. Angew. Chem. Int. Ed. 2020. 59, 17472-17476.

13. Park, D.; Park, H.; Lee, Y.; Kim, S.-O.; Jung, H.-G.; Chung, K. Y.; Shim, J. H.; Yu, S. Theoretical Design of Lithium Chloride Superionic Conductors for All-Solid-State High Voltage Lithium-lon Batteries. ACS Appl. Mater. Interfaces 2020. 12, 34806-34814.

14. Asano, T.; Sakai, A.; Ouchi, S.; Sakaida, M.; Miyazaki, A.; Hasegawa, S. Solid Halide Electrolytes with High Lithium-lon Conductivity for Application in $4 \mathrm{~V}$ Class Bulk-Type All-Solid-State Batteries. AdV. Mater. 2018, 30, 1803075. 
15. Steiner, H.-J.; Lutz, H. D. Neue schnelle Ionenleiter vom Typ $\mathrm{Ml}_{3} \mathrm{MIIICl}_{6}(\mathrm{MI}=\mathrm{Li}, \mathrm{Na}, \mathrm{Ag} ; \mathrm{MIII}=\mathrm{In}, \mathrm{Y}) . Z$. Für Anorg. Allg. Chem. 1992, 613, 26-30.

16. Plichta, E. J.; Behl, W. K.; Vujic, D.; Chang, W. H. S.; Schleich, D. M. The Rechargeable $\mathrm{Li}_{x} \mathrm{TiS}_{2} / \mathrm{LiAlCl}_{4} / \mathrm{Li}_{1}-\mathrm{COO}_{2}$ Solid-State Cell. J. Electrochem. Soc. 1992, 139, 1509-1513.

17. Kanno, R.; Takeda, Y.; Yamamoto, O. Ionic Conductivity of Solid Lithium Ion Conductors with the Spinel Structure: $\mathrm{Li}_{2} \mathrm{MCl}_{4}$ (M = Mg, Mn, Fe, Cd). Mater. Res. Bull. 1981, 16, 999-1005.

18. Bohnsack, A.; Stenzel, F.; Zajonc, A.; Balzer, G.; Wickleder, M. S.; Meyer, G. Ternäre Halogenide Vom Typ $A_{3} M X_{6}$. VI [1]. Ternäre Chloride Der Selten-Erd-Elemente Mit Lithium, $L_{3} \mathrm{MCl}_{6}(\mathrm{M}=\mathrm{Tb}-\mathrm{Lu}, \mathrm{Y}, \mathrm{Sc})$ : Synthese, Kristallstrukturen Und lonenbewegung. Z. Für Anorg. Allg. Chem. 1997, 623, 1067-1073.

19. Li, X.; Liang, J.; Luo, J.; Norouzi Banis, M.; Wang, C.; Li, W.; Deng, S.; Yu, C.; Zhao, F.; Hu, Y.; Sham, T.; Zhang, L.; Zhao, S.; Lu, S.; Huang, H.; Li, R.; Adair, K. R.; Sun, X. Air-Stable $\mathrm{Li}_{3} \mathrm{InCl}_{6}$ Electrolyte with High Voltage Compatibility for All-Solid-State Batteries. Energy Environ. Sci. 2019. 12, 2665-2671.

20. Li, X.; Liang, J.; Chen, N.; Luo, J.; Adair, K. R.; Wang, C.; Banis, M. N.; Sham, T.-K.; Zhang, L.; Zhao, S.; Lu, S.; Huang, H.; Li, R.; Sun, X. Water-Mediated Synthesis of a Superionic Halide Solid Electrolyte. Angew. Chem. Int. Ed. 2019, 58, 16427-16432.

21. Park, K.-H.; Kaup, K.; Assoud, A.; Zhang, Q.; Wu, X.; Nazar, L. F. High Voltage Superionic Halide Solid Electrolytes for All-Solid-State Li-Ion Batteries. ACS Energy Lett. 2020, 5, 533-539.

22. Li, X.; Liang, J.; Adair, K. R.; Li, J.; Li, W.; Zhao, F.; Hu, Y.; Sham, T.-K.; Zhang, L.; Zhao, S. Origin of Superionic $\mathrm{Li}_{3} \mathrm{Y}_{1}-\mathrm{x} \mathrm{In}_{\mathrm{x}} \mathrm{Cl}_{6}$ Halide Solid-Electrolytes with High Humidity Tolerance. Nano Lett. 2020, 20, 384-4392.

23. Liang, J.; Li, X.; Wang, S.; Adair, K. R.; Li, W.; Zhao, Y.; Wang, C.; Hu, Y.; Zhang, L.; Zhao, S. SiteOccupation-Tuned Superionic $\mathrm{Li}_{x} \mathrm{ScCl}_{3+x}$ Halide Solid Electrolytes for All-Solid-State Batteries. J. Am. Chem. Soc. 2020, 142, 7012-7022.

24. Nazar, L.; Zhou, L.; Kwok, C. Y.; Shyamsunder, A.; Zhang, Q.; Wu, X. A New Halospinel Superionic Conductor for High-Voltage All Solid State Lithium Batteries. Energy Environ. Sci. 2020, 13, 20562063.

25. Xiao, Y.; Wang, Y.; Bo, S.-H.; Kim, J. C.; Miara, L. J.; Ceder, G. Understanding Interface Stability in SolidState Batteries. Nat. Rev. Mater. 2020, 5, 105-126.

26. Muy, S.; Voss, J.; Schlem, R.; Koerver, R.; Sedlmaier, S. J.; Maglia, F.; Lamp, P.; Zeier, W. G.; Shao-Horn, Y. High-Throughput Screening of Solid-State Li-lon Conductors Using Lattice-Dynamics Descriptors. iScience 2019. 26, 270-282.

27. Rehr, J. J.; Albers, R. C. Theoretical Approaches to X-Ray Absorption Fine Structure. Rev. Mod. Phys. $2000,72,621$.

28. Joly, Y. X-Ray Absorption Near-Edge Structure Calculations Beyond the Muffin-Tin Approximation. Phys. Rev. B 2001, 63, 125120.

29. Jonscher, A. K. The 'Universal' Dielectric Response. Nature, 1977, 267, 673-679. 
30. Jonscher, A. K. A New Understanding of the Dielectric Relaxation of Solids. J. Mater. Sci. 1981, 16, 2037-2060.

31. Brug, G. J.; Van Den Eeden, A. L. G.; Sluyters-Rehbach, M.; Sluyters, J. H. The Analysis of Electrode Impedances Complicated by the Presence of a Constant Phase Element. J. Electroanal. Chem. 1984, $176,275-295$.

32. Irvine, J. T. S.; Sinclair, D. C.; West, A. R. Electroceramics: Characterization by Impedance Spectroscopy. Adv. Mater. 1990, 2, 132-138.

33. de Klerk, N. J. J.; van der Maas, E.; Wagemaker, M. Analysis of Diffusion in Solid-State Electrolytes through MD Simulations, Improvement of the Li-lon Conductivity in $\beta-\mathrm{Li}_{3} \mathrm{PS}_{4}$ as an Example. ACS Appl. Energy Mater. 2018, 1, 3230-3242.

34. Schlem, R.; Muy, S.; Prinz, N.; Banik, A.; Shao-Horn, Y.; Zobel, M.; Zeier, W. G. Mechanochemical Synthesis: A Tool to Tune Cation Site Disorder and Ionic Transport Properties of $\mathrm{Li}_{3} \mathrm{MCl}_{6}(\mathrm{M}=\mathrm{Y}, \mathrm{Er})$ Superionic Conductors. Adv. Energy Mater. 2019, 10, 1903719.

35. Jain, A.; Ong, S. P.; Hautier, G.; Chen, W.; Richards, W. D.; Dacek, S.; Cholia, S.; Gunter, D.; Skinner, D.; Ceder, G. Commentary: The Materials Project: A materials genome approach to accelerating materials innovation. APL Mater. 2013, 1, 011002.

36. Raimund, K.; Zhang, W.; de Biasi, L.; Schweidler, S.; Kondrakov, A. O.; Kolling, S; Brezesinski, T.; Hartmann, P.; Zeier, W. G.; Janek, J. Chemo-Mechanical Expansion of Lithium Electrode Materials-on the Route to Mechanically Optimized All-Solid-State Batteries. Energy Environ. Sci. 2018, 11, 21422158.

\section{Figures}



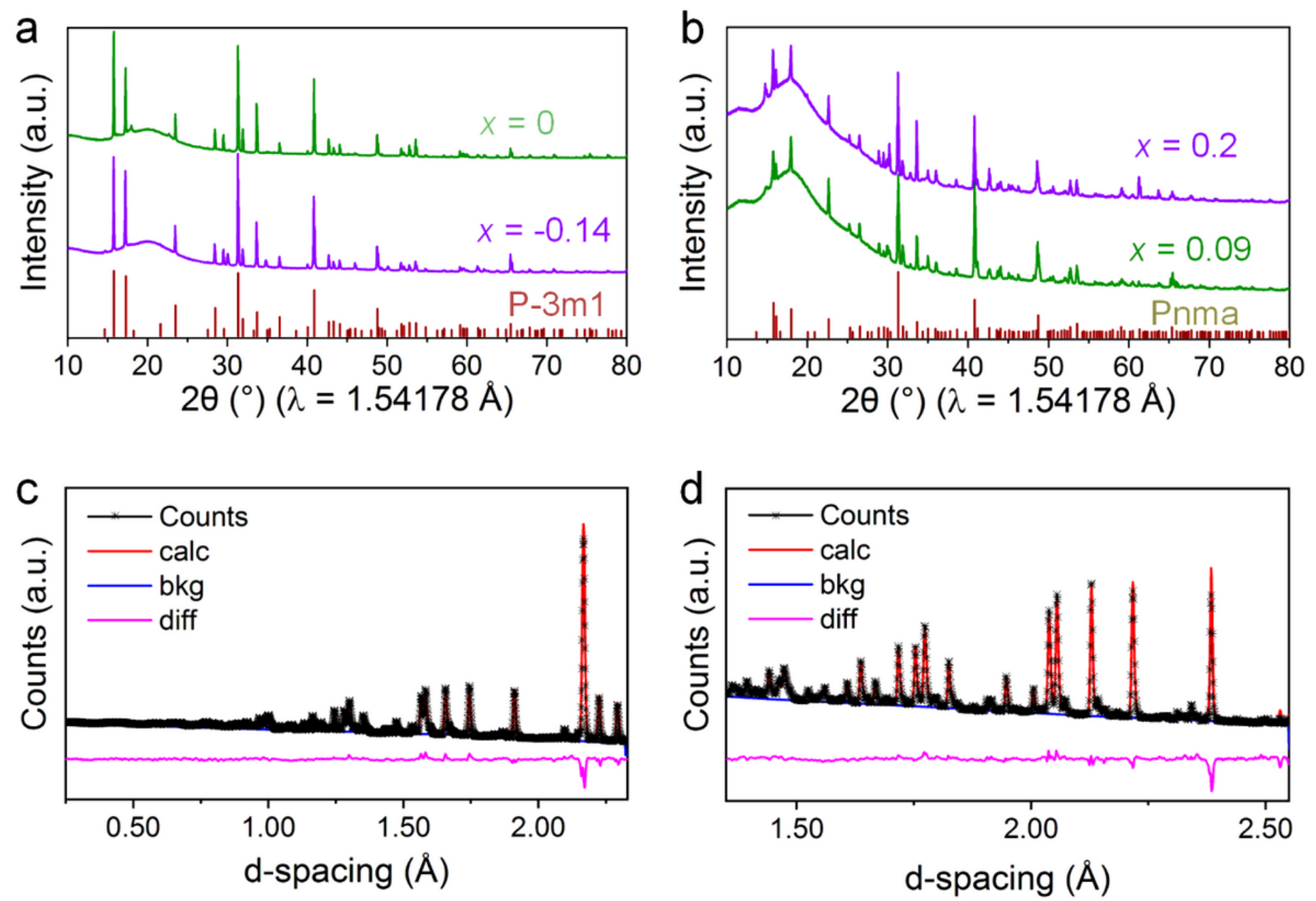

Figure 1

XRD and neutron diffraction patterns of the Li-Ho-Cl system. (a) XRD patterns of $\mathrm{Li} 3 \mathrm{HoCl} 6(\mathrm{x}=0)$ and $\mathrm{Li} 3.42 \mathrm{Ho} 0.86 \mathrm{Cl} 6(\mathrm{x}=-0.14)$ samples. Both patterns were indexed to the same space group of P-3m1. (b) XRD patterns of $\mathrm{Li} 2.4 \mathrm{Ho} 1.2 \mathrm{Cl} 6(\mathrm{x}=0.2)$ and $\mathrm{Li} 2.73 \mathrm{Ho} 1.09 \mathrm{Cl} 6(\mathrm{x}=0.09)$ samples. The patterns were indexed to the same space group of Pnma. (c-d) Fited time-of-flight NPD patterns of the two highest resolution detector banks with d-spacing ranges of 0.3-3.4 $\AA$ (c), 0.75-2.55 $\AA$ (d) and the fit resulting from the Rietveld refinement. 
a

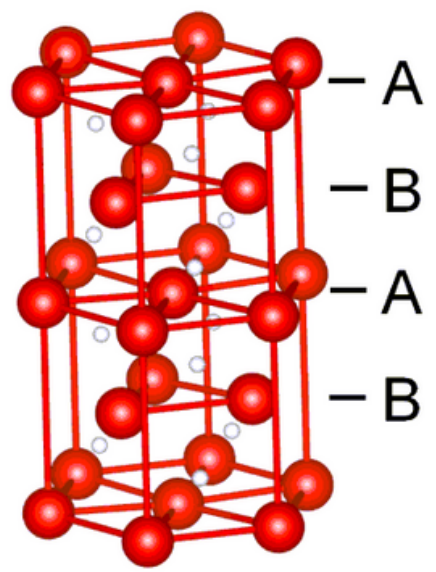

b

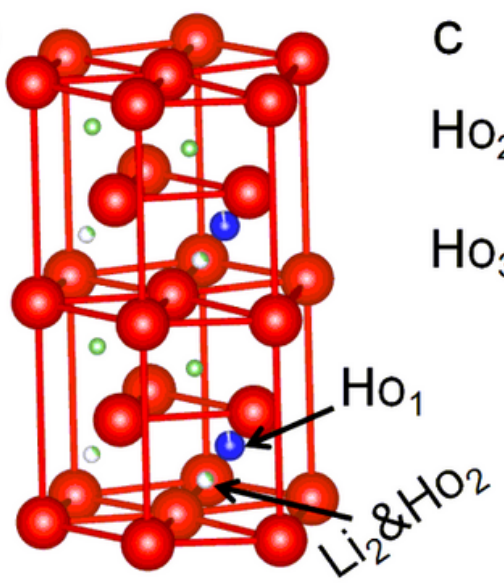

hcp anion sub-lattice orthorhombic phase trigonal phase
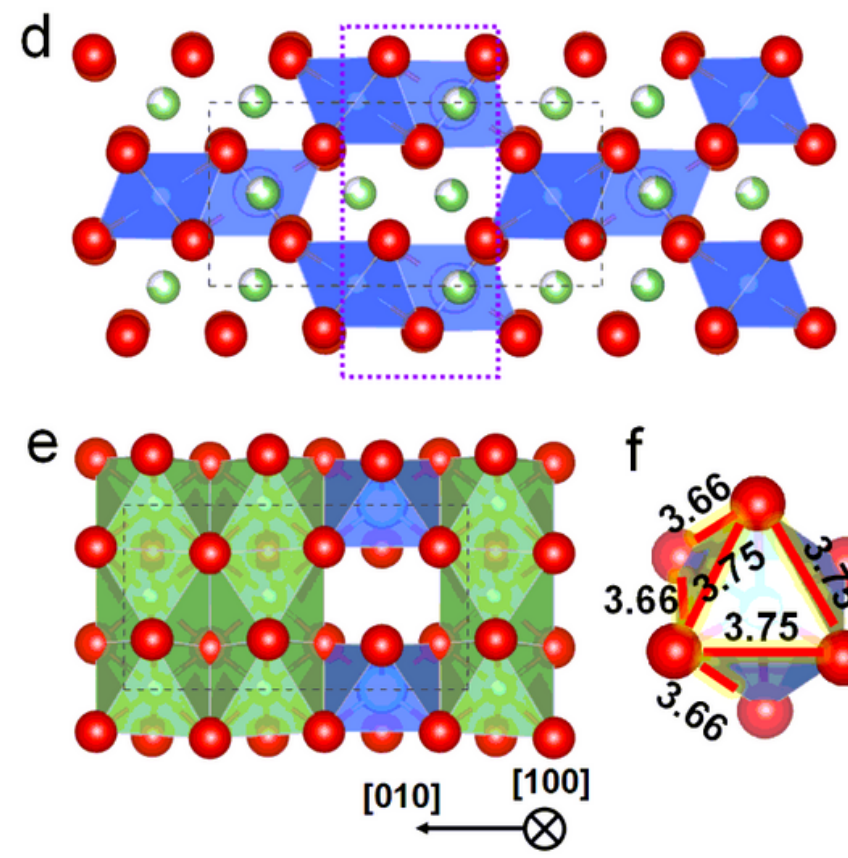

orthorhombic phase $\mathrm{Li}-\mathrm{HO}-\mathrm{Cl}$

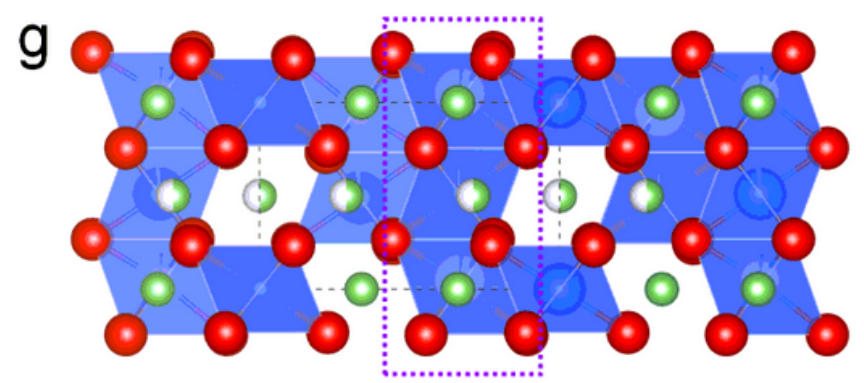

h०००००0000 i

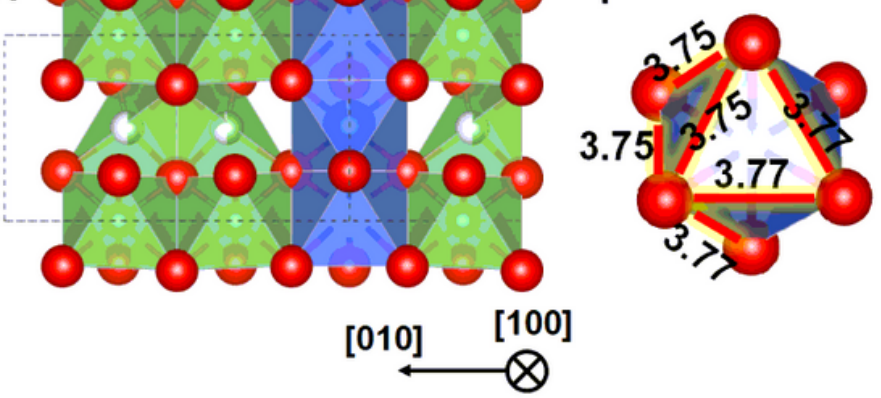

trigonal phase $\mathrm{Li}-\mathrm{Ho}-\mathrm{Cl}$

Figure 2

The structure and anion/cation arrangement of orthorhombic and trigonal structure of Li3HoCl6. (a-c) the different cation arrangement of Ho and vacancy site in orthorhombic and trigonal structure. (d, e) Orthorhombic structure of Li2.42Ho1.13 Cl6 unit cell. (f) HoCl63- octahedron in orthorhombic phase of Li2.42 Ho1.13 Cl6. $(\mathrm{g}, \mathrm{h})$ Trigonal structure of $\mathrm{Li} 3 \mathrm{HoCl} 6$ unit cell. (i) HoCl63- octahedron in trigonal phase of Li3HoCl6. Green Li, blue Ho, red Cl. 

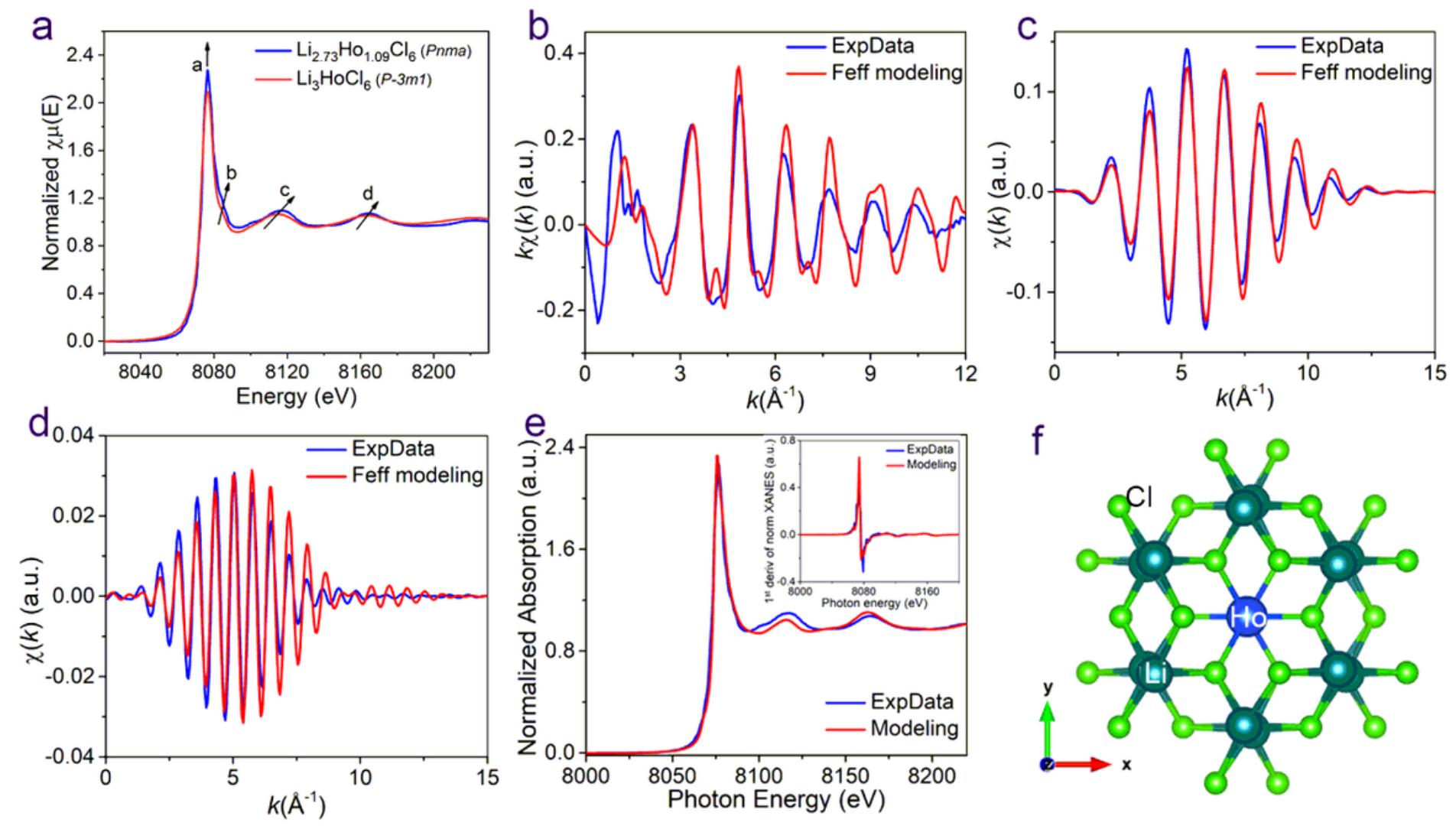

\section{Figure 3}

Local environment of Ho in the Li-Ho-Cl components based on XAFS fitting. (a) Typical Ho L3-edge XAFS spectra of Pnma phase Li2.73Ho1.09Cl6 ( $x=0.09)$ and P-3m1 phase Li3HoCl6 $(x=0)$ samples. (b) The overall $k \chi(k)$ between the experimental (blue line) and the Feff modeling (red line) of Ho local environment of Li2.73Ho1.09Cl6 (Pnma). (c) BFT filtered kx(k) for the 1st shell FT of Li2.73Ho1.09Cl6

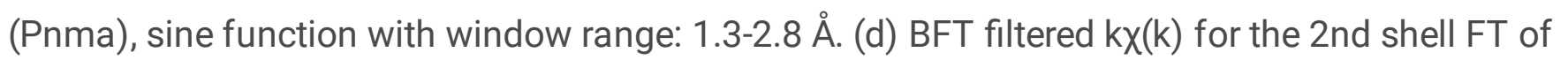
Li2.73Ho1.09 Cl6 (Pnma), sine function with window range: 3.6-5.0 $\AA$. (e) Comparison between the experimental XANES (blue line) and the best fit of the XANES theoretical modeling (red line). ( $f$ ) The first and second shell of the Ho sub-structural system (Ho centered spherical cluster with a radius of $R=6 \AA$ ). 

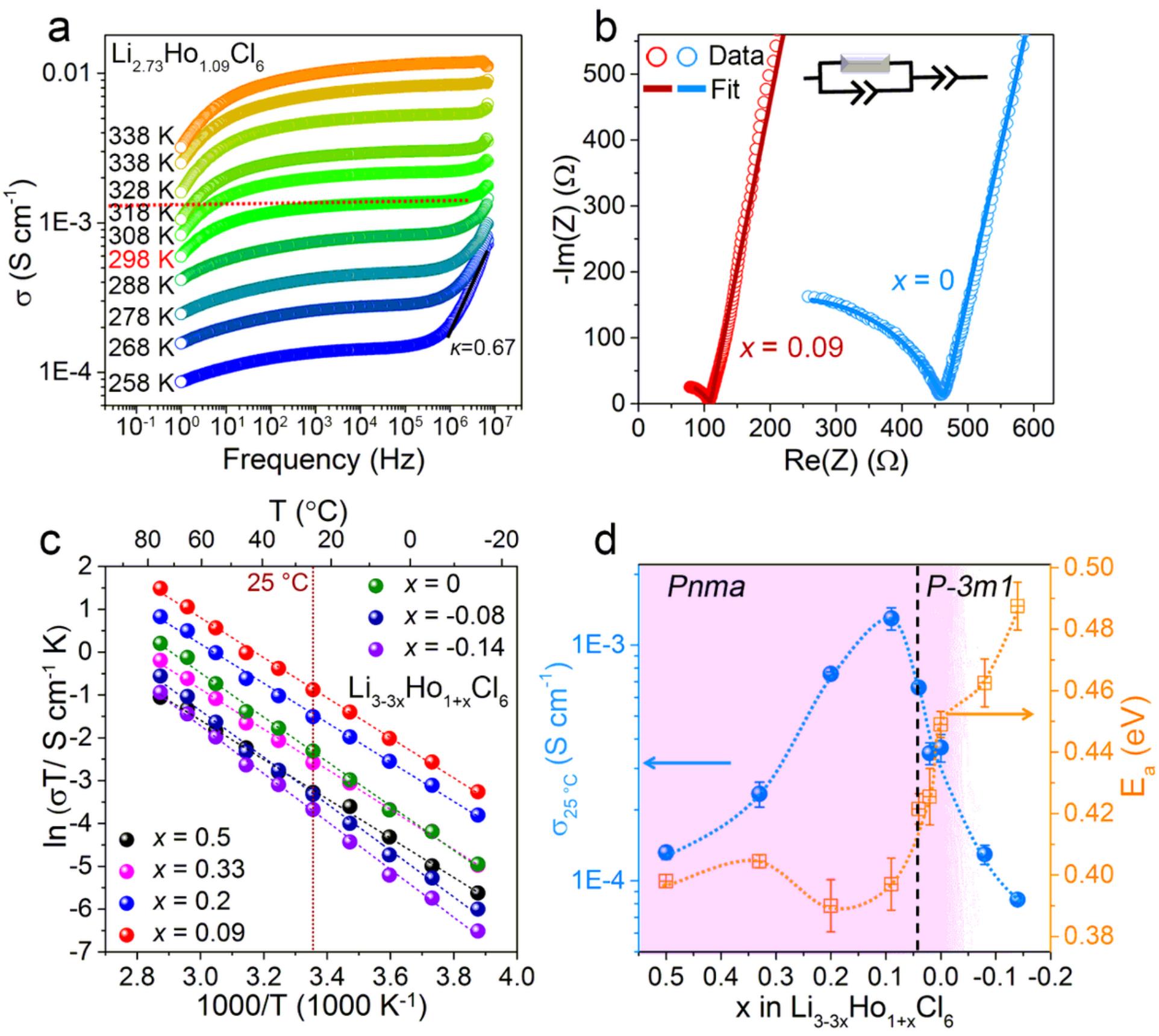

\section{Figure 4}

(a) Conductivity isotherms $\sigma(v)$ of the as-prepared Li2.73Ho1.09Cl6 $(x=0.09)$ SSE recorded at different temperatures. (b) Representative Nyquist-plots for the as-prepared Pnma phase Li2.73Ho1.09Cl6 ( $\mathrm{x}=$ $0.09)$ and $\mathrm{P}-3 \mathrm{~m} 1$ phase $\mathrm{Li} 3 \mathrm{HoCl} 6(\mathrm{x}=0)$ SSEs at $25^{\circ} \mathrm{C}$. (c) Arrhenius-plots of the Li3-3xHo1+xCl6 SSEs $(-0.14 \leq x \leq 0.5)$. (d) The RT ionic conductivities and corresponding activation energies of the Li3$3 \mathrm{xHo} 1+x \mathrm{Cl} 6$ SSEs $(-0.14 \leq \mathrm{x} \leq 0.5)$. 

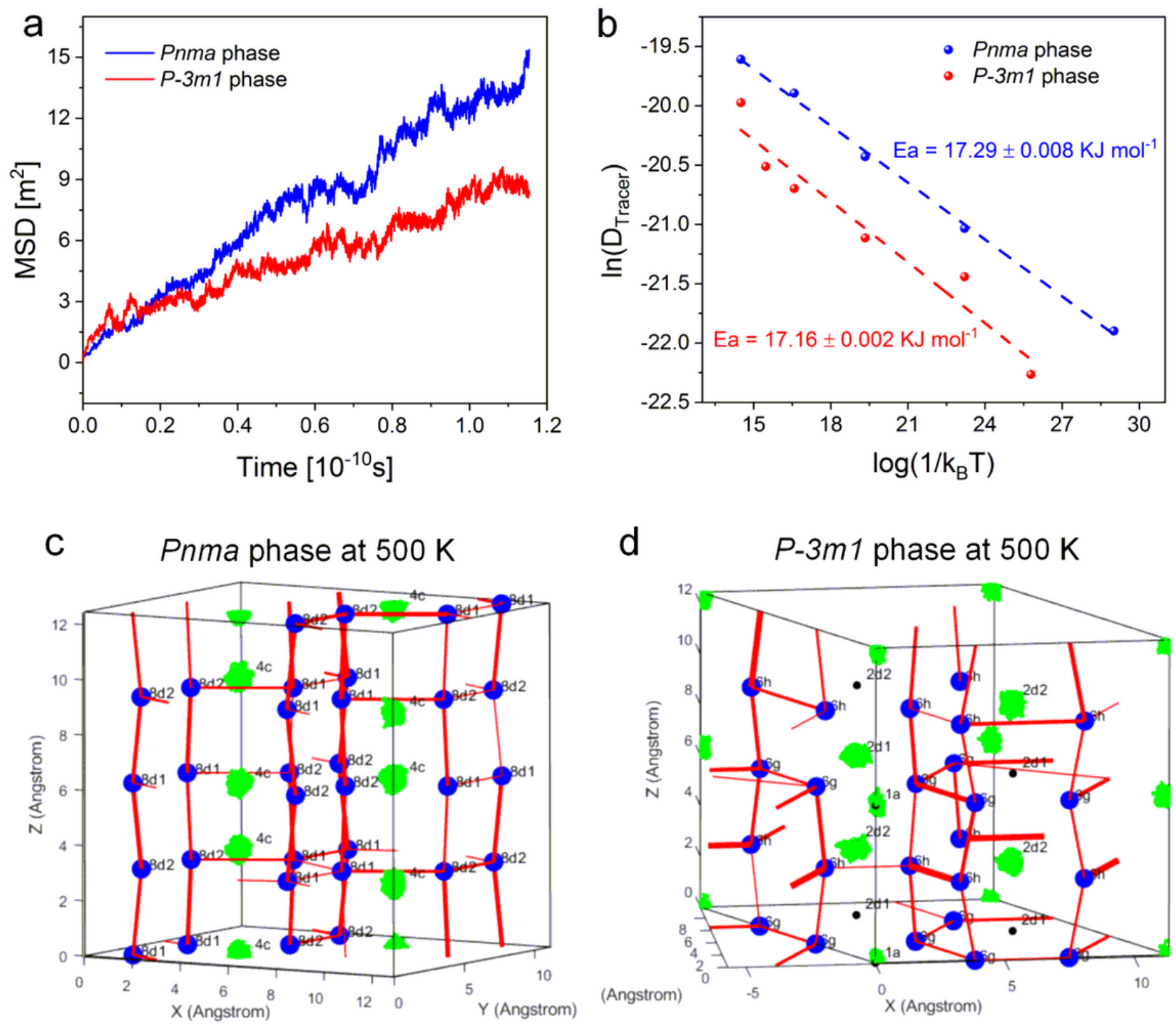

Figure 5

(a) Mean squared displacement (MSD) at 500K. (b) Logarithm of the Tracer diffusion coefficient vs. 1/kbT for different temperatures The Li-sites (blue), Ho-trajectories (green), and Li-ion jumps that occurred during the simulation (red). The size of the Li-sites and the thickness of the Lines represent the occupancy of the site during the simulation and the jump frequency, respectively. 


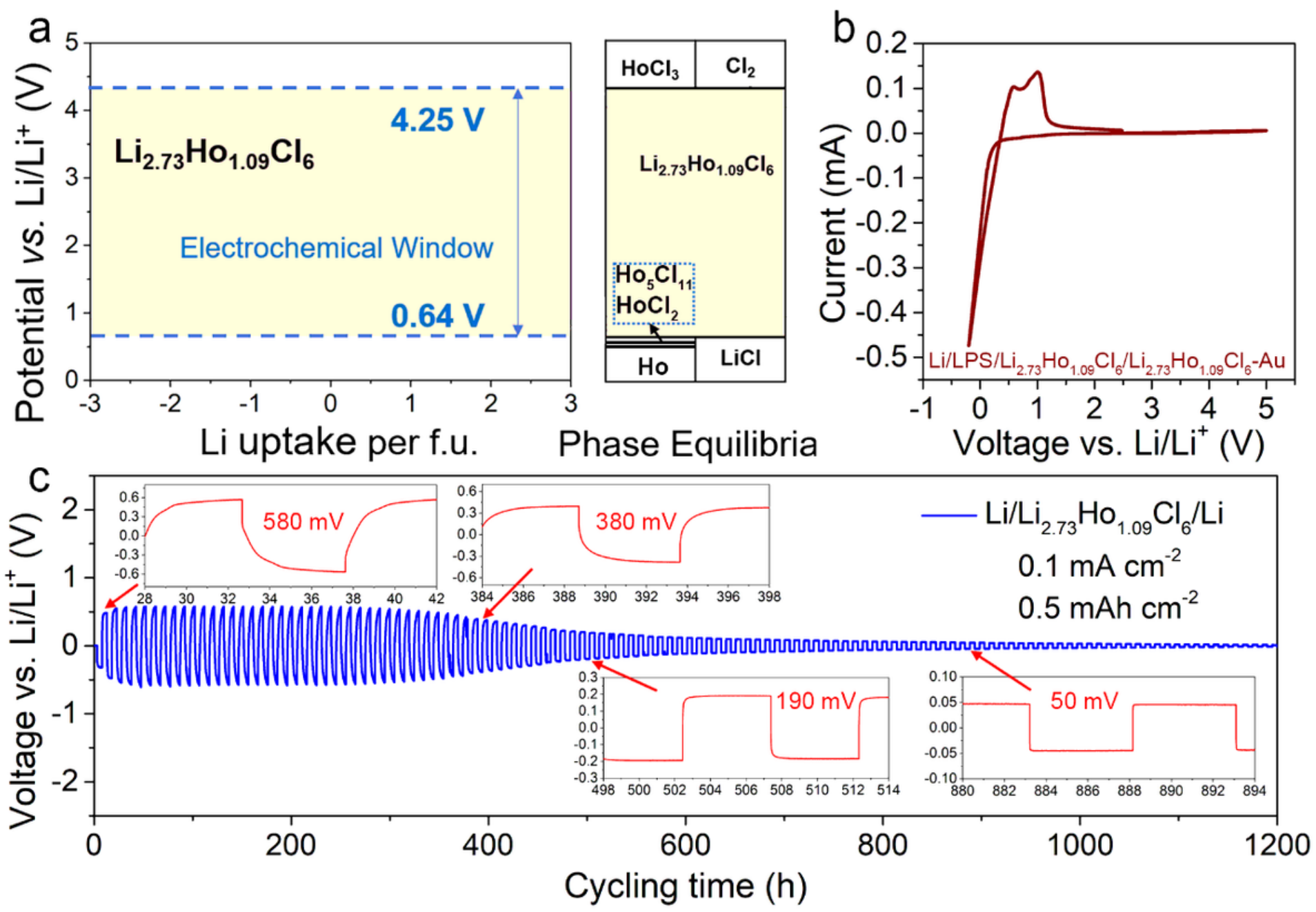

Figure 6

Electrochemical performance of Li2.73Ho1.09 Cl6 ( $x=0.09)$ SSE. (a) Thermodynamic equilibrium voltage profile and the phase equilibria for $\mathrm{Li} 2.73 \mathrm{Ho} 1.09 \mathrm{Cl} 6(x=0.09)$ by first-principle calculations. (b) CV curve of the Li/Li7P3S11/Li2.73Ho1.09Cl6/Li2.73Ho1.09Cl6-Au cell at $0.1 \mathrm{mV} \mathrm{s}-1$ (Li2.73Ho1.09Cl6 to Au mass ratio of 1:1). (c) Electrochemical performance of the symmetric all-solid-state $\mathrm{Li} / \mathrm{Li} 2.73 \mathrm{Ho} 1.09 \mathrm{Cl} 6 / \mathrm{Li}$ cell at a current density of $0.1 \mathrm{~mA} \mathrm{~cm}-2$ and capacity of $0.5 \mathrm{mAh} \mathrm{cm}-2$. 

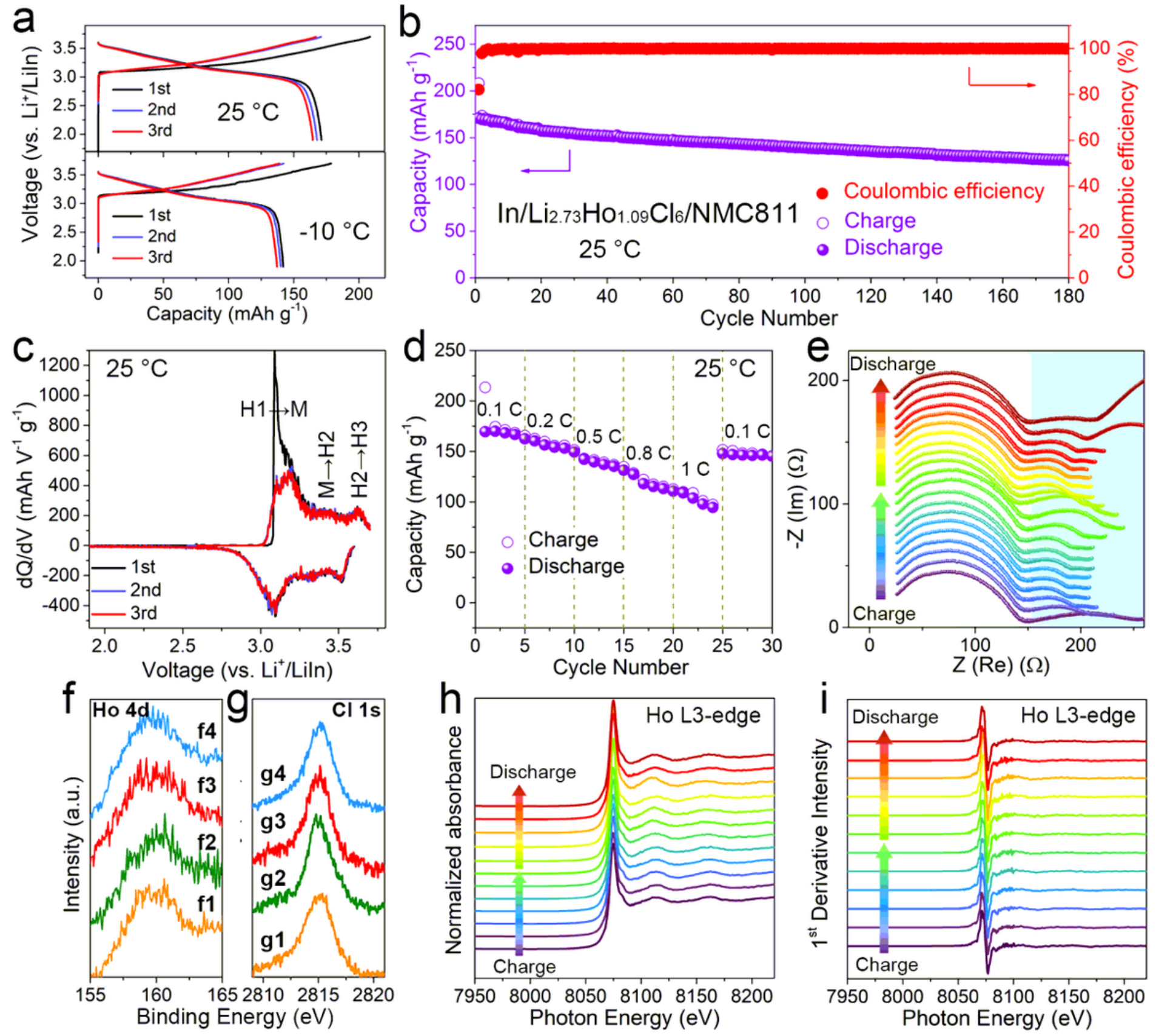

\section{Figure 7}

Electrochemical performance of NMC811/Li2.73Ho1.09Cl6/In ASSLBs at $25^{\circ} \mathrm{C}$. (a) The charge/discharge curves and (b) the cycling performance recorded at $25^{\circ} \mathrm{C}(0.1 \mathrm{C})$. (c) The dQ/dV curves for the first three cycles at $0.1 \mathrm{C}$ at $25^{\circ} \mathrm{C}$. (d) Rate capability at $0.1,0.2,0.5,0.8$, and $1 \mathrm{C}$ at $25^{\circ} \mathrm{C}$. (e) EIS spectra of NMC811/Li2.73Ho1.09Cl6/In ASSLB carried out after $2 \mathrm{~h}$ of charge/discharge and $2 \mathrm{~h}$ of rest. $(f, g)$ HEXPS of Ho 4d and $\mathrm{Cl} 1 \mathrm{~s}$ spectra of NMC811-Li2.73Ho1.09Cl6 cathode at photon energy of 3000 $\mathrm{eV}$ recorded at different charge/discharge states, i.e., $(\mathrm{f} 1, \mathrm{~g} 1)$ pristine, $(\mathrm{f} 2, \mathrm{~g} 2)$ after first charge, $(\mathrm{f} 3, \mathrm{~g} 3)$ 
after first discharge, and (f4, g4) fully discharged after 50 cycles. Ex-situ (h) Ho L3-edge and (i) the first derivatives of Ho L3-edge XANES spectra of NMC811-Li2.73Ho1.09Cl6 cathode composites at different charge-discharge states.
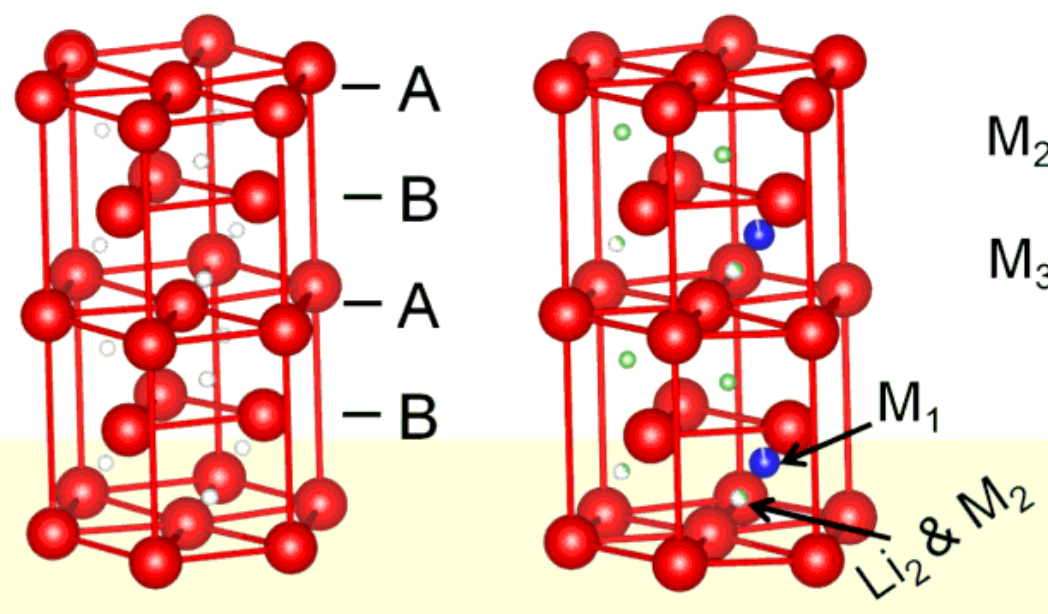

hcp anion sub-lattice

orthorhombic phase

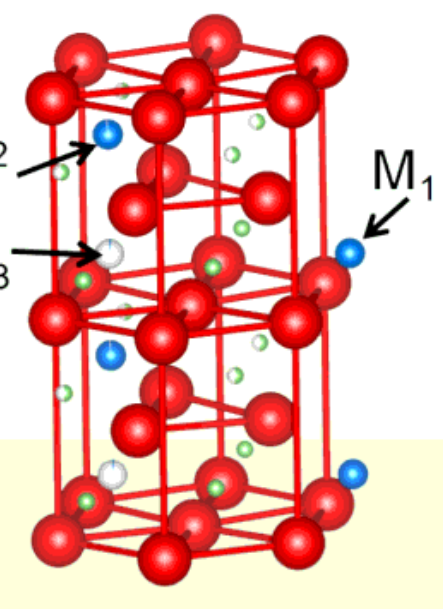

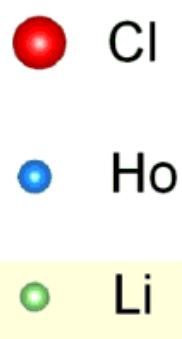

Vacancy

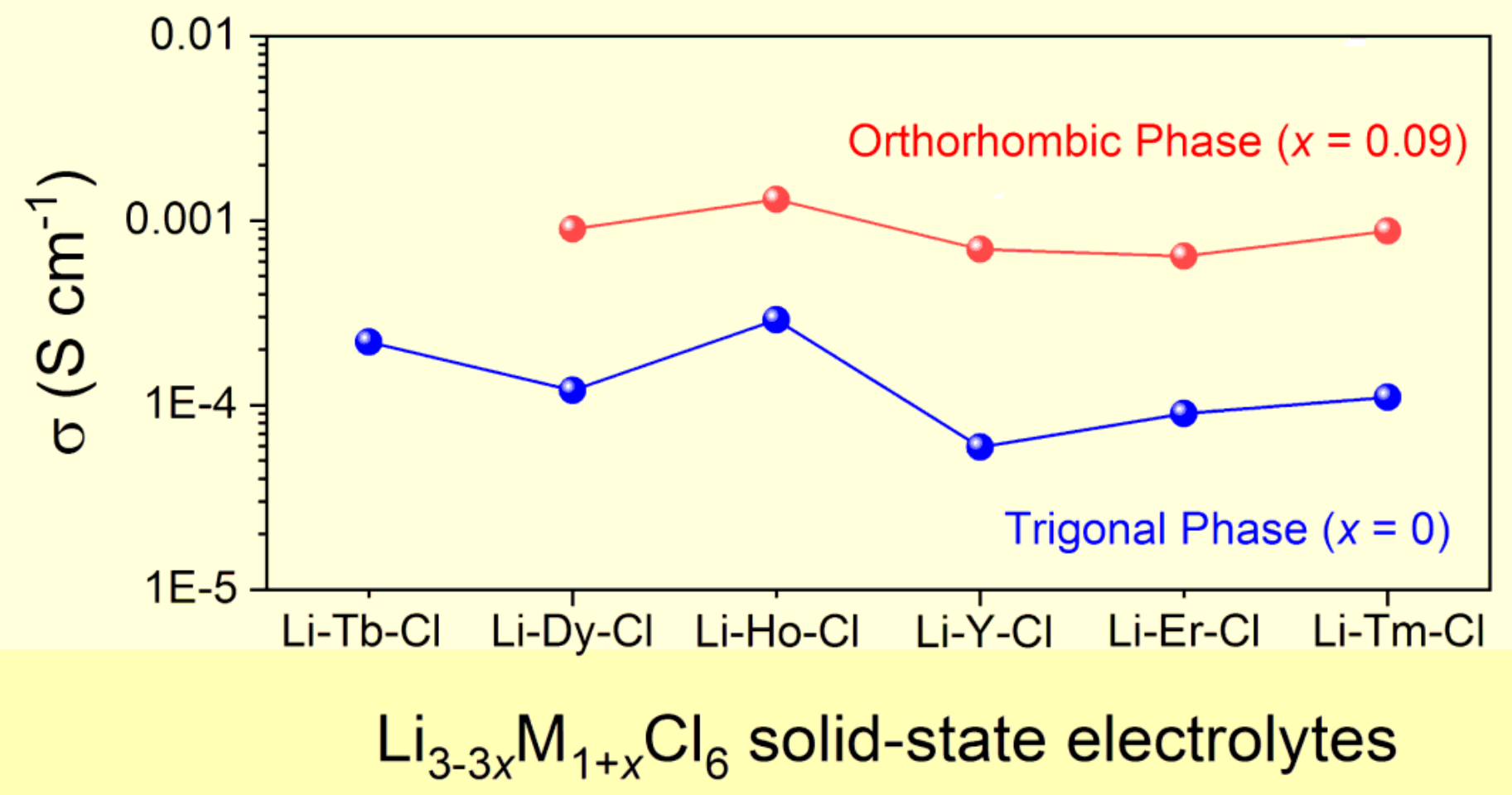

Figure 8

Graphical Abstract Ternary rare-earth metal chloride series of Li3-3xM1+xCl6 $(-0.14<x \leq 0.5, M=T b$, Dy, $\mathrm{Ho}, \mathrm{Y}, \mathrm{Er}, \mathrm{Tm}$ ) reveal a phase transition from trigonal to new orthorhombic structure upon increasing $\mathrm{x}$ values for M-rich environments. The orthorhombic phase formation triggers a significant increase in $\mathrm{Li}+$ diffusivity and reduces the activation energy barrier. A large number of materials with high ionic conductivity have been found here, illustrating the breakthrough of good halide conductors. 


\section{Supplementary Files}

This is a list of supplementary files associated with this preprint. Click to download.

- SupportingInformation.docx 